Article

\title{
Optimization of Polymer Processing: A Review (Part I- Extrusion)
}

\author{
António Gaspar-Cunha ${ }^{1 *}$, José A. Covas ${ }^{2}$ and Janusz Sikora ${ }^{3}$ \\ 1 Institute of Polymers and Composites, University of Minho, agc@dep.uminho.pt, jcovas@dep.uminho.pt \\ 2 Institute of Polymers and Composites, University of Minho, jcovas@dep.uminho.pt \\ 3 Department of Technology and Polymer Processing, Faculty of Mechanical Engineering, Lublin University \\ of Technology, Nadbystrzycka 36, 20-618 Lublin, Poland, janusz.sikora@pollub.pl \\ * Correspondence: agc@dep.uminho.pt; Dept. of Polymer Engineering, Campus de Azurém, University of \\ Minho, Guimarães, Portugal
}

\begin{abstract}
Given the global economic and societal importance of the polymer industry, the continuous search for improvements in the various processing techniques is of practical primordial importance. This review evaluates the application of optimization methodologies to the main polymer processing operations. The most important characteristics related with the usage of optimization techniques, such as the nature of the objective function, the type of optimization algorithm, the modelling approach used to evaluate the solutions, and the parameters to optimize, are discussed. The aim is to identify the most important features of an optimization system for polymer processing problems, and define the best procedure for each particular practical situation. For this purpose, a state-of-the-art of the optimization methodologies usually employed is first presented, followed by an extensive review of the literature dealing with the major processing techniques, the discussion being completed by considering both the characteristics identified and the available optimization methodologies. This first part of the review focus on extrusion, namely extruders, extrusion dies and calibrators. It is concluded that there is a set of methodologies that can be confidently applied in polymer processing, with a very good performance and without the need of demanding computation requirements.
\end{abstract}

Keywords: polymer processing, single screw, twin screw, injection molding, blow molding, thermoforming, optimization, artificial intelligence

\section{Introduction}

Polymer processing is an important industrial activity that converts raw materials, such as polymers, polymer compounds, polymer blends, composites and nanocomposites, into useful products mostly for applications in packaging, building and construction, mobility, electrical and electronics, medical, agriculture, household, leisure and sports. For example, in 2019 more than 55000 European companies (plastics raw materials producers, plastics converters, recyclers and machinery manufacturers in the EU28 Member States) employed over 1.5 million people, and converted $50.7 \mathrm{Mt}$ of plastics [1]. A progressively more sustainable and better performing range of polymer systems, together with increasingly more efficient and intelligent extrusion, injection molding, blow molding and thermoforming - the most important processing techniques for thermoplastics are paramount to create or improve products with more advanced performances and functionalities.

Thermoplastics processing typically involves three functional steps: plasticization of a solid polymer (usually supplied in pellet form), flow and shaping of the melt, and cooling. Thus, an understanding of polymer processing requires a good knowledge of heat transfer, melt rheology, fluid mechanics, morphology development, among others. In the case of reactive extrusion, plasticization is combined with chemical reactions (polymer synthesis and/or modification) into a single process. In their seminal book on polymer 
processing, Tadmor and Gogos [2] proposed a structural breakdown of polymer processing into elementary steps, based on the principles of transport phenomena, fluid mechanics, heat and mass transfer, polymer melt rheology, solid mechanics, physics and chemistry of polymers and mixing, which provide the basic tools for quantitatively analyzing polymer processing.

It is well recognized that the geometry of the processing equipment, the operating conditions selected, and the properties of the polymer system being processed determine the resulting morphology of the part, and hence its practical performance. This has fostered extensive experimental investigation with the aim of obtaining a good understanding of the physical, thermal, rheological and chemical processes developing during polymer processing. Historically, the screw extraction experiments carried out by Maddock [3] were particularly relevant to shed light on plasticating extrusion. Once physical models of the underlying phenomena were available, they were translated into mathematical descriptions, either analytical or numerical, depending on the assumptions and simplifications made. Currently, modelling of polymer processing is well developed [2, 4-6], simulation software devoted to various processing techniques being commercially available. These programs solve the governing equations that describe the phenomena developing along the various individual process stages, coupled to the relevant boundary conditions (operating conditions and equipment geometry) and constitutive equations for the polymer properties. The resulting predictions provide a description of how the process will perform under the conditions defined, which is obviously very useful to both processors and equipment/tool manufacturers. In some cases, the morphology of the part (macromolecular/fibre orientation, crystallization rate, size of the spherulites, etc.) can be predicted from the knowledge of the thermomechanical process parameters, but the link to the enduse engineering properties entails multi-scale modelling [7], which is still very costly computationally.

The direct use of these simulations for practical process troubleshooting, setting the operating conditions, defining a screw profile, designing an extrusion die, an injection mold, or a plastic bottle, would require to tackle the inverse problem, i.e., to solve the set of governing equations of the process in order to the geometrical and operational variables, while prescribing the required performance as boundary condition(s). This is complex and usually mathematically ill-posed, as there is no unique relationship between cause and effect. Thus, in practice, four alternative methodologies can be adopted:

1. Use the simulation tools on a trial and error basis. This is obviously expensive and inefficient, and relies on the capability of the user to input progressively more appropriate boundary conditions;

2. Develop specific design approaches, i.e., using the modelling equations in a prearranged sequence. Examples are methods to design extruder screws [8] or extrusion dies [9];

3. Adopt an optimization procedure, whereby the process modelling package is used judiciously by an optimization algorithm, in order to define a "best" solution, or a Pareto optimal solution (see below). Practical polymer processing problems generally involve multi-, often conflicting, criteria (for example maximize output, while minimizing viscous dissipation and mechanical energy consumption in plasticating single screw extrusion), hence this approach is usually labelled as multi-objective optimization.

4. Perform data-driven optimization, which consists in the use of Artificial Intelligence (AI) techniques to explore the search space based on experimental or computational data $[10,11]$.

Some of these methodologies were already presented in several reviews analyzing the application of optimization techniques in polymer processing. Kasat et al. [12] discussed the application of Genetic Algorithms (GAs) in polymer science and engineering, stressing the existence of multiple objectives and constraints that must be dealt with simultaneously. Particularly in the area of chemical reactions during polymerization, obtaining a polymer with a desired molecular weight requires satisfying simultaneously various 
objectives, such as minimizing the reaction time as it implies lower cost, and minimizing the concentration of side products as they decrease the product properties. Oduguwa et al. [13] extended the idea applying Evolutionary Algorithms (EA) to the manufacturing industry, which includes polymer processing. The main justification given for the use of this type of algorithms comes from the fact that the traditional methods frequently employed to solve complex real world problems tend to miss a more efficient exploration of the search space, becoming trapped in sub-optimal regions, while simultaneously they are often computationally expensive. Methodologies based on the use of a population of points (solutions), such as EAs, can overcome this situation, as these points can evolve simultaneously towards the Pareto optimal front, and thus access the global optimal solutions. Oduguwa et al. [13] also refer the difficulties that optimization approaches face in being accepted in industry. Recently, Nastaj and Wilczyński [14] addressed the optimization and scale-up of single and twin screw extrusion. However, they focused on methodologies developed by specific authors, and the optimization concepts discussed were somewhat limited. Thus, in general, previous reviews on the optimization of polymer processing excluded several important technological or optimization aspects, are very limited in terms of the analysis performed, and even ignore several important published contributions.

After introducing some important concepts of multiobjective optimization, the present review covers the application of optimization methods to solve real problems in polymer processing, encompassing extrusion, injection molding, blow molding and thermoforming. Due to the extension of the analysis, the work is divided into two parts. The present part 1 focus on extrusion, namely single and twin screw extruders, extrusion dies and calibrators. The most important contributions to the field are identified and future trends are discussed.

\section{Need for Optimization in Polymer Processing}

The practical need for optimization, namely in what concerns the process, the design variables, the modelling requirements and the objectives to be attained, will be illustrated with an example dealing with Injection Stretch Blow-Molding, a technique widely used for the manufacture of bottles for plain and carbonated drinks (and dealt with in greater detail in Part 2). Figure 1 illustrates the main production steps (A to E, following the open arrows). An injection unit (A) fills the cavity of an injection mold (B) to produce a preform. This is then transferred to a blow-mold (C) where it is stretched and blown (D) against the contours of the mold cavity. Once the container is sufficiently cold, the mold opens (E), the part is removed and a new production cycle is initiated. Modelling this process in order to predict the performance of the part for a given set of input conditions (bottle design, operating conditions, equipment geometry, material properties) typically entails the numerical modelling of each of its individual steps, followed by coupling them through appropriate boundary conditions. Depending on the physical process models considered and consequent ability of the numerical routines, the thickness profile of the product, its morphology, and the mechanical performance could be predicted.

Such a sophisticated tool would be used quite inefficiently if conventional means were adopted. For example, if the aim is to produce a bottle with a minimum weight and a maximum thickness uniformity, the computer model will be used on a trial-end-error basis, with the operator progressively fine tuning the operating conditions and/or bottle design until attaining a satisfactory result. A much more efficient strategy would be to consider again the modelling sequence and solve the inverse problem, whereby the bottle characteristics are imposed as boundary conditions and the equations are solved in order to the operating conditions. This would imply approaching the process backwards, from $\mathrm{F}$ to $\mathrm{A}$, as indicated by the curved black arrows in Fig.1. However, this is mathematically ill-posed, as there are no unique relationships between cause and effect.

Alternatively, an optimization problem can be defined, consisting of two objectives (minimize bottle weight and maximize its thickness uniformity) and a restriction (the minimum thickness must be higher than a pre-defined value). The decision variable is the $3 \mathrm{D}$ 
thickness distribution of the part that results from all prior process steps, which constitutes a huge decision variables space. The optimization can either proceed following steps (i) to (v) in Fig.1, or the system can be considered as a whole and all steps can be optimized simultaneously.

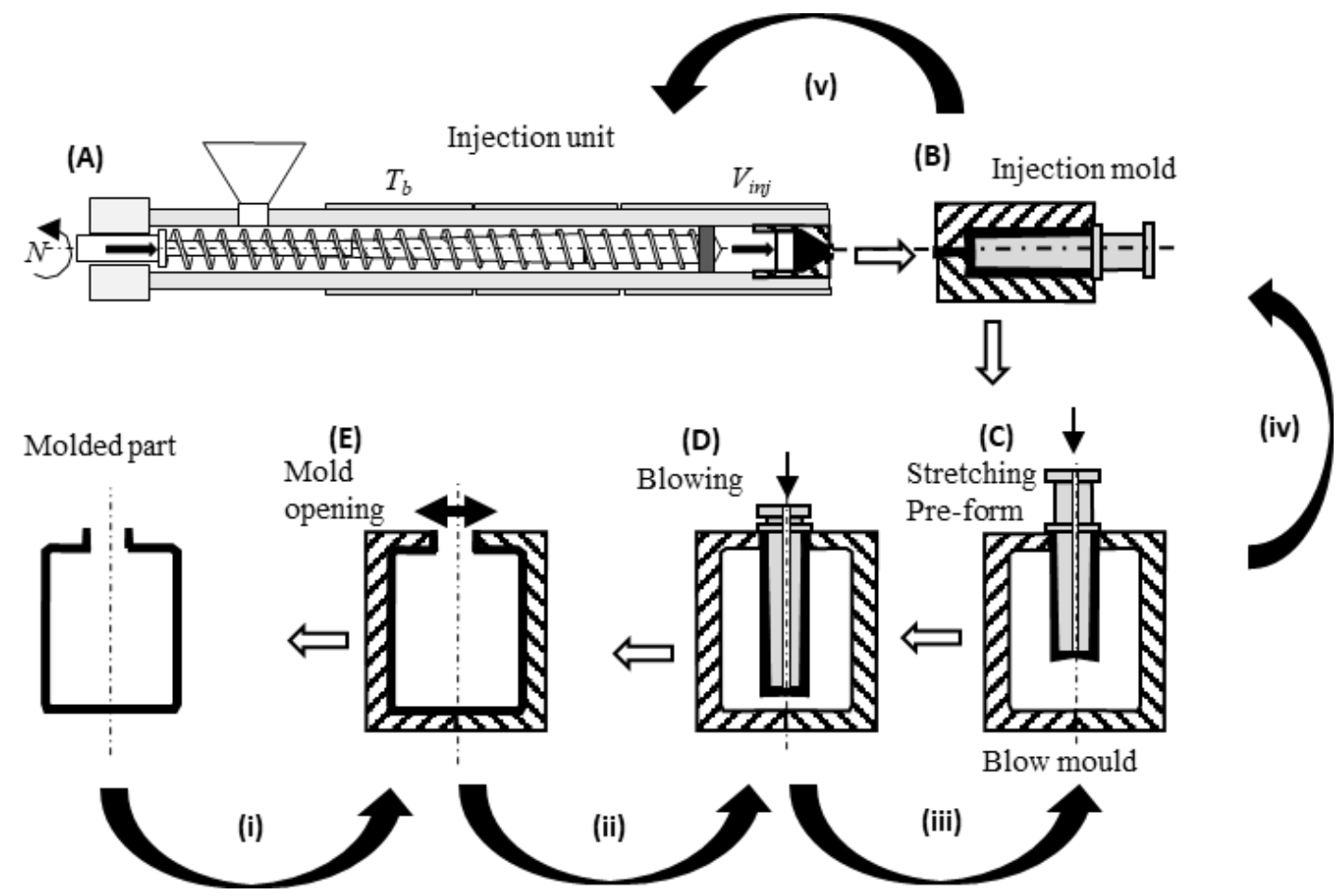

Figure 1. Optimization of Injection Stretch Blow-Molding. (A) to (E) illustrate the process steps. Open arrows follow the process sequence; black curved arrows follow the optimization sequence.

Fig. 2 shows results obtained for the optimization of steps (i) and (ii). In step (i) the aim is to define the thickness profile of the bottle that minimizes its weight, the maximum strain under a given load and the thickness uniformity in terms of a parameter RMSE. Using EAs, an initial population of solutions is generated randomly, evolving until the $100^{\text {th }}$ generation. From the analysis of the Pareto front, solution S3-i was selected. The following optimization problem concerns the blowing phase (here considered to take place after stretching the pre-form), i.e., the optimization of the thickness profile of the preform that produces the optimal bottle thickness profile found in the first step. For that purpose, the mean $\left(f_{1}\right)$ and the maximum $\left(f_{2}\right)$ errors between the optimal thickness distribution and the thickness distribution of the parison must be minimized. More details on this optimization can be found elsewhere $[15,16]$. 


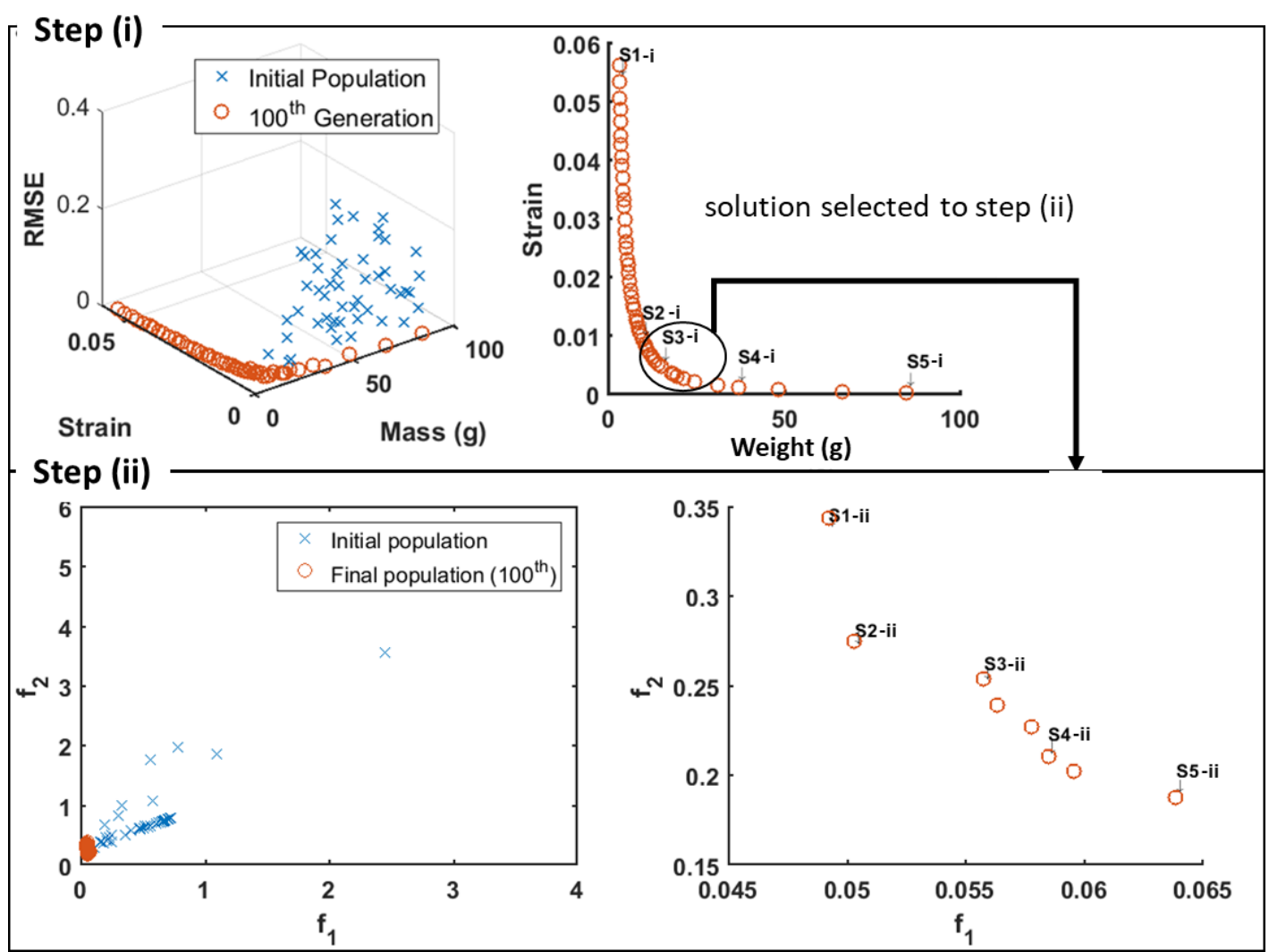

Figure 2. Typical results for the blow-molding optimization example: solution S3-i is selected for step (ii), from which a new Pareto set is obtained.

\section{Multi-Objective Optimization}

The aim of optimization is to find the best set of decision variables, i.e., a solution, that optimizes an objective function on a given search space, often in the presence of equality and/or inequality constraints, with the main purpose of approaching that solution to a global optimum [17]. Without loss of generality, in the case of a maximization problem, the mathematical formulation is the following:

$$
\begin{array}{ccc}
\text { maximise } & f\left(x_{i}\right) & i=1, \ldots, N \\
\text { subject to } & g_{j}\left(x_{i}\right) \geq 0 & j=1, \ldots, J \\
& h_{k}\left(x_{i}\right)=0 & k=1, \ldots, K
\end{array}
$$

where $f$ is the objective function of the $N$ parameters $x_{i}, g_{j}$ are the $J(J \geq 0)$ inequality constraints, and $h_{k}$ are the $K(K \geq 0)$ equality constraints.

In the absence of a systematic procedure, a traditional way of finding the best possible solution consists in performing a statistical and/or regression analysis based on experimental or computational results. From a set of data, it is possible to deduce a mathematical model relating the objective function $(f)$ with the decision variables $\left(x_{i}\right)$. From this model, an approximation to the optimal solution can be found both graphically and mathematically. This simple approach relates linearly the objectives with the decision variables. The quality of the solution depends strongly on the number of solutions available to construct the model. Consequently, more elaborated models can be deduced if more solutions are available. This type of regression methods has different forms of being identified in the literature: design of experiments, response surface, statistical analysis, data fitting, etc.

Another kind of methodologies uses some type of information to perform the search. In most classical algorithms, the problem is solved starting with a solution generated randomly in the search space and, by means of a moving rule in a unidirectional direction based on the use of local information, the algorithm progresses point-by-point to find the best solution (figure 3-A). This new optimized solution will be the starting point for the 
next step, where the same procedure is repeated a number of pre-defined times. If more than one objective exists, they must be aggregated into a single objective. The differences between the available algorithms rely on the way this search direction is defined. Two types of such methods exist: direct and gradient based. In the first case, the search is only guided based on the values of the objective function and constraints, e.g., simplex search, pattern search and conjugate direction methods. These methods are usually slow, requiring a high number of function evaluations. The second type involves the use of information concerning the first and/or second derivative of the objective functions values and/or constraints, e.g., steepest descent and conjugate gradient methods. The use of derivatives hastens convergence, but these methods are unable to deal with non-differentiable and discontinuous problems. The calculation of the derivatives must be possible, which does not often happen in real problems [17]. These methods face other difficulties: i) the convergence is strongly dependent on the initial solution chosen, ii) the solution found is often stuck in a local sub-optimum, iii) the algorithm is unable to deal with a discrete problem and cannot take properly into account its multi-objective nature. In fact, real world optimization problems (such as polymer processing) can comprise linear and/or non-linear objective functions and constraints, discrete and/or continuous variables, stochastic or deterministic inputs, and single or multiple objectives. Thus, the choice of the algorithm to use will depend strongly on the problem features [17].

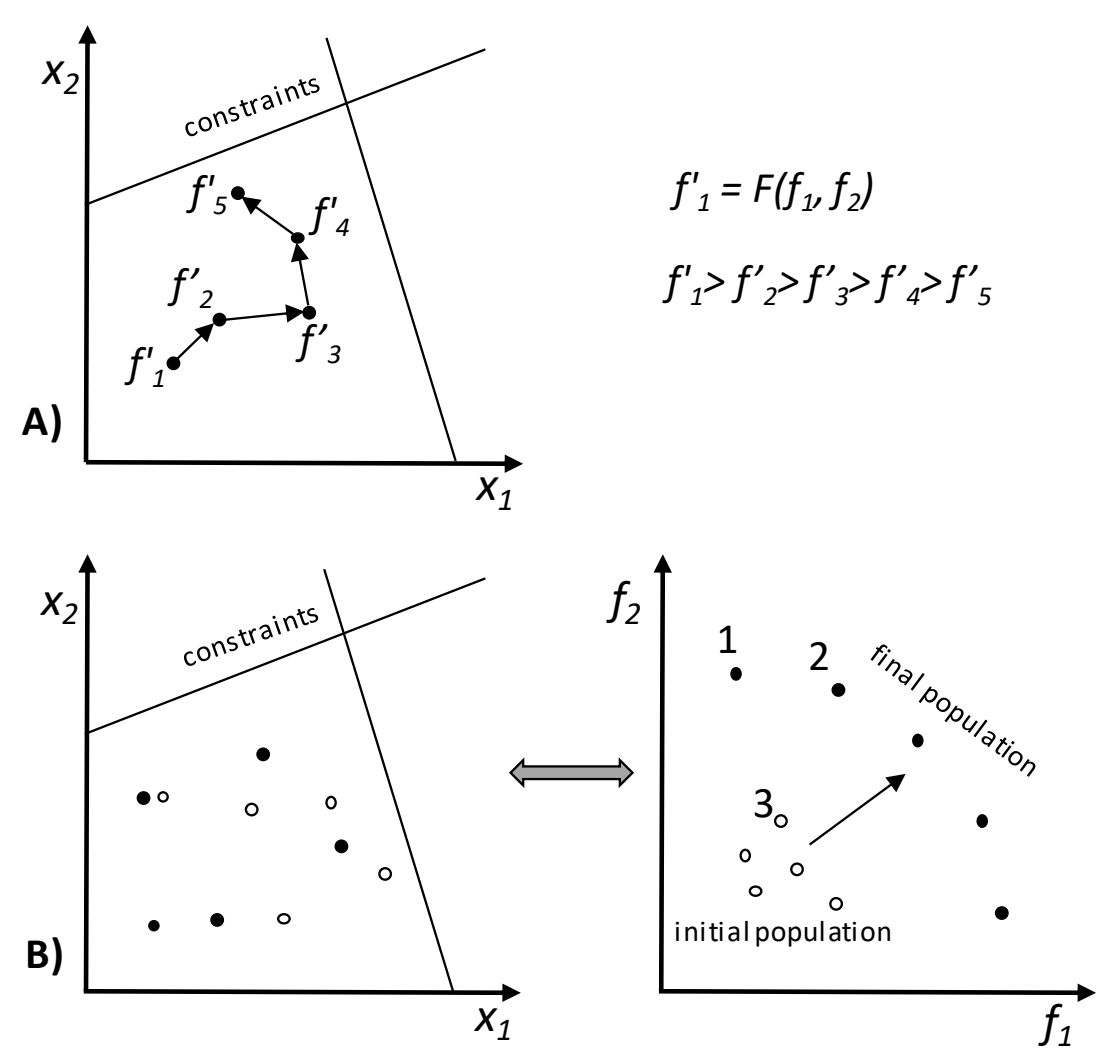

Figure 3. A) Single objective optimization versus B) multi-objective optimization.

Most (if not all) real optimization problems are multiobjective, i.e., it is necessary to satisfy simultaneously several performance measures (objectives), which are often conflicting. Also, their relative importance to the process may be subjective and can be dealt with in different ways. Mathematically, a multiobjective optimization problem can be defined as [18, 19]: 


$$
\begin{array}{ccc}
\text { maximise } & f_{m}\left(x_{i}\right) & i=1, \ldots, N ; \quad m=1, \ldots, M \\
\text { subject to } & g_{j}\left(x_{i}\right)=0 & j=1, \ldots, J \\
& h_{k}\left(x_{i}\right) \geq 0 & k=1, \ldots, K
\end{array}
$$

where $M$ is the number of objectives.

The various objectives can be taken into account a priori, a posteriori or iteratively. In the first case, the optimization takes place after the decision maker (DM) defines the relative importance of the objectives using, for example, weights or goals. The performance of the solutions can be obtained through the use of aggregation functions, e.g., weighted sum, weighted product, or weighted Tchebycheff metric [20]. Then, a traditional single-objective methodology can be used to find the optimum, as illustrated in figure 3A. A weighted sum is simple, but not only it is difficult to set the weight vectors to obtain a Pareto-optimal solution in a desired region of the objective space, it does not allow to find certain Pareto-optimal solutions in a nonconvex and/or discontinuous objective space. The weighted Tchebycheff metric guarantees finding all Pareto-optimal solutions, assuming that the ideal solution in this multidimensional space $\left(\mathrm{z}^{*}\right)$ is known. However, some weaknesses also exist: i) the minimum and maximum values of the objectives and of $z^{*}$ must be known, ii) for a small number of objectives, not all Pareto-optimal solutions are obtained, and iii) as the number of objectives increases, the problem becomes nondifferentiable $[18,19]$. The second alternative consists in optimizing simultaneously all the objectives without considering beforehand the preferences of the DM. The results will be a set of solutions denoted as Pareto set, were two spaces of interest exist, instead of a single one as before, i.e., the decision variables and the objectives domain, as depicted in figure 3-B. Thus, the aim of multi-objective optimization is to find feasible solutions where all objective functions are optimized. These solutions are incomparable to each other, since it is not possible to state that one is better than another in all objectives simultaneously. The Pareto solutions are the set of non-dominated solutions (the full circles in figure 3-B). In the figure, Solution 2 is better than solution 3 in both objectives, thus solution 3 is dominated by solution 1 . The same does not happen when comparing solutions 1 and 2, as none of these solutions dominates the other. In this case, the selection of a solution can only be made using additional preference information that must be provided a posteriori by the DM [20]. Finally, the optimization and choice of solutions steps can be made iteratively and interleaved, i.e., the optimization algorithm provides alternative solutions to the decision maker, who indicates his/her preferences, and the optimization algorithm runs again taking into account this information. The process is repeated until a satisfactory solution (or solutions) is/are found. The decision making can be performed by humans and/or by computer algorithms [21].

The better known and more widely used multi-objective optimization algorithms are based on Evolutionary Algorithms (EA). These are meta-heuristics that mimic the process of natural evolution of a population of individuals, the solutions, along successive generations. They comprise Genetic Algorithms (GA), Evolutionary Programming (EP), Evolution Strategies (ES) and Genetic Programming (GP). Figure 4 illustrates schematically how this type of algorithms works. The individuals with higher performance in the environment will have more capacity to survive, which implies that they also have more capacity to be reproduced into the next generations. As in natural evolution, the offspring (new solutions) are generated by genetic operators such as crossover and mutation, inheriting most of the parent characteristics. The population of individuals, which are the potential solutions to the problem under study, evolves using the mechanisms of selection and variation. The selection operators enable the best individuals to have higher probability of being selected for generating offspring and the variation operators allow the generation of new individuals $[18,19,22]$. Selection is based on the quality of each individual, which is given by a fitness function that is associated with the objective or objective functions for single or multi-objective optimization, respectively. 


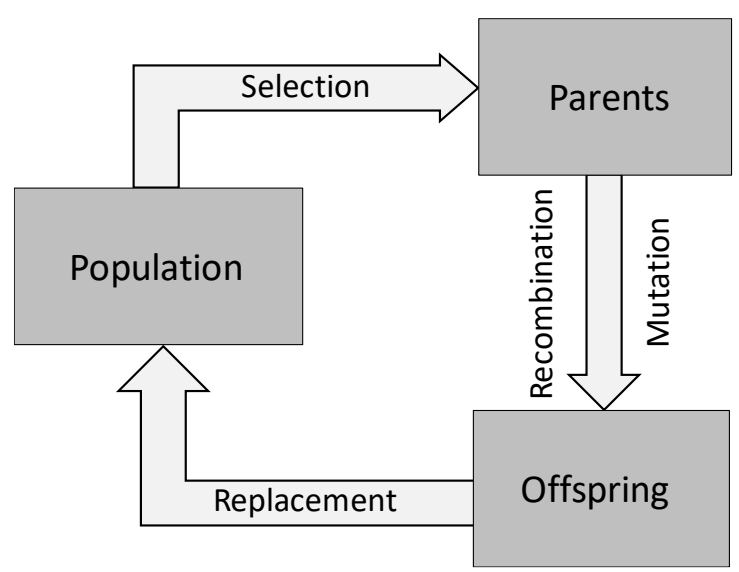

Figure 4. The evolutionary cycle.

Based on the advantage of working with a population of solutions, multi-objective procedures were developed whereby the solutions evolve towards the optimal Pareto front in a single run. They are usually known as Multi-Objective Evolutionary Algorithms (MOEAs). In order to spread the population of solutions along the entire Pareto front, an additional operator measuring diversity is considered. The performance of the algorithm will depend on the balance between convergence, given by the value of the objective functions, and diversity, a measure of the distance between the solutions on the search space. Convergence and diversity are combined into a single fitness operator that is responsible for the selection of the solutions to be reproduced for the subsequent generations. This can be done in three ways: i) based on Pareto dominance [22, 23], ii) scalarizing [24] and iii) using indicator algorithms [25,26,27]. The research on MOEAs allowed the development of other types of multi-objective algorithms, such as Ant Colony Optimization (ACO) [28], Particle Swarm Optimization (PSO) [29], Simulated Annealing (SA) [30] and Differential Evolution (DE) [31].

Another important optimization topic concerns the robustness of the solutions obtained, i.e., the capacity of the solutions found of being robust against, for example, changes in the design variables. This may signify that the best solutions are not the ones selected, but, instead, other solutions that perform well for different ranges of the design variables. Robustness can be taken into account through expectation measures, which quantify simultaneously fitness and robustness, or by variance measures, which assess the deviation of the original fitness in the neighborhood of the solution. Several combinations of expectation and variance measures have been linked to a MOEA, and applied to a few multi-objective problems, in order to select the most performing approach [32]. Gaspar-Cunha et al. [33] developed a set of benchmark problems to account for diverse types of robustness circumstances. The methodology was also assessed through application to some real problems. Figure 5 explains the concept in a multi-objective environment: solution 1 is more robust than solution 2 , as the same variation in the decision variables domain produces less variation in the objectives domain.

Since the result of a MOEA is a set of solutions, the decision maker is always challenged with the need to select the best (single) solution from this Pareto set. For this purpose, it is necessary to introduce, at some point of the optimization process, the preferences of one (or more) decision maker(s). A methodology based on a weighted stress function method was used for fitness assignment in MOEA [34]. This approach provides a fast convergence and a better final approximation performance, as measured by the usual quality indicators, when compared with traditional methods, such as aggregation functions. 


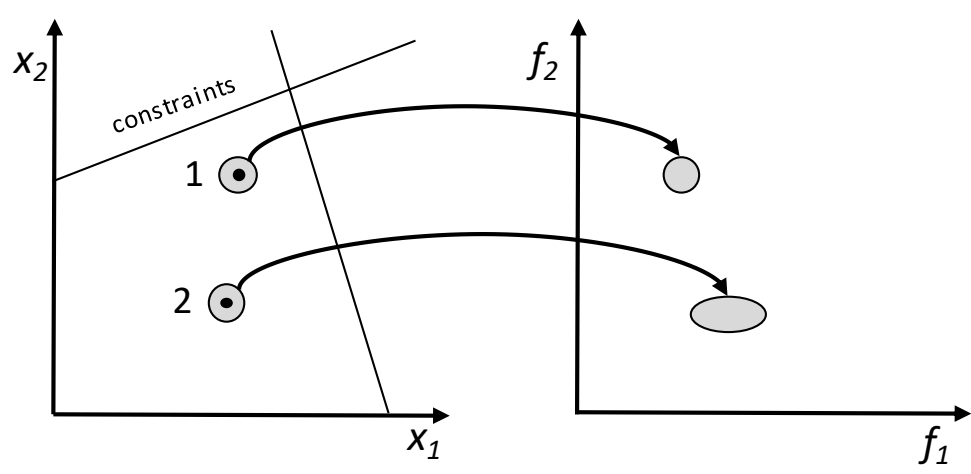

Figure 5. Concept of robustness in multi-objective environment. Solution 1 is more robust than solution 2 , as the same variation in the decision variables domain $\left(x_{1}, x_{2}\right)$ produces less variation in the objectives domain $\left(f_{1}, f_{2}\right)$.

\section{Optimization Algorithms in Polymer Processing}

\subsection{Methodology}

Figure 6 displays the polymer processing sequences targeted by the present review, as they can entail optimization problems. They include single screw (A) and twin screw (B) extrusion, injection molding (C), blow molding (either based on extrusion (A3) or injection molding (C2)) and thermoforming (A2) (which produces 3D shapes from previously extruded sheets). Typically, these processes involve a plasticating step (carried out by the plasticating unit - which is an extruder, in the case of (A) and (B)), which encompasses material feed, melting, mixing, pressure generation and pumping, followed by shaping and cooling. All these stages can be approached as optimization problems. In the case of the plasticating unit, it may be necessary to define the screw profile, or set the operating conditions for a given polymer system/product combination. When extruding profiles (A1), the design of the extrusion die and calibrator can be approached as optimization problems. Indeed, die design aims at defining the geometry of the flow channel that assures uniform melt velocity (and, if possible, also equal residence time) across the entire extrudate cross-section at the die exit. Similarly, the extrusion of flat film/sheet (A2) with uniform thickness (or a pre-defined thickness variation) along its width requires a proper design of the die. Intermeshing co-rotating twin screw extruders are extensively used in compounding and reactive extrusion operations (B), the outcome of the process consisting of a new material in pellet form, to be subsequently converted into a final product by one of the available processing techniques. Since the geometry of these machines must be adapted to the requirements of each production, which may vary significantly, the screws and barrel are often built as assemblies of individual elements (which are supplied with different conveying, distributive and dispersive mixing abilities). Thus, screw design consists of selecting a given number of screw elements from a larger set of possibilities, and position them in the right sequence. This constitutes an interesting, albeit complex, optimization problem. In injection molding (C), mold design (C1), screw design and setting the operating conditions are well recognized optimization problems. Finally, blow molding also entails optimization challenges, as discussed in section 2 .

The discussion of the efforts reported in the open literature to solve the above optimization problems will be performed, whenever possible, using the following type of data (and respective acronyms):

1. Objective function. It can be Single Objective (SO), Aggregated Product (AP), Aggregated Sum (AS) or Multi-Objective (MO);

2. Optimization algorithm, e.g., Empirical, Regression, Direct, Gradient, Augmented Lagrangian (AL), Pattern Search (PS), Expert System (ES), Evolutionary Algorithm (EA), Differential Evolution (DE), Ant Colony Optimization (ACO), Stochastic Local Search (SLS), Two-Phase Local Search (TPLS); 
3. Modeling approach: unidimensional (1D), two-dimensional (2D) and three-dimensional (3D), using Analytical (A), Finite Differences (FD), Finite Volumes (FV) or Finite Elements (FE) approaches;

4. Decision variables, i.e., parameters to optimize. The aim can be to define the Operating Conditions (OC), Screw Design (SD), Screw Configuration (SC) (the last two will be explained below), Die Geometry (DG). The number of variables considered in the problem is indicated between brackets in the tables below;

5. Other characteristics, related with the process/modeling, the optimization, or others;
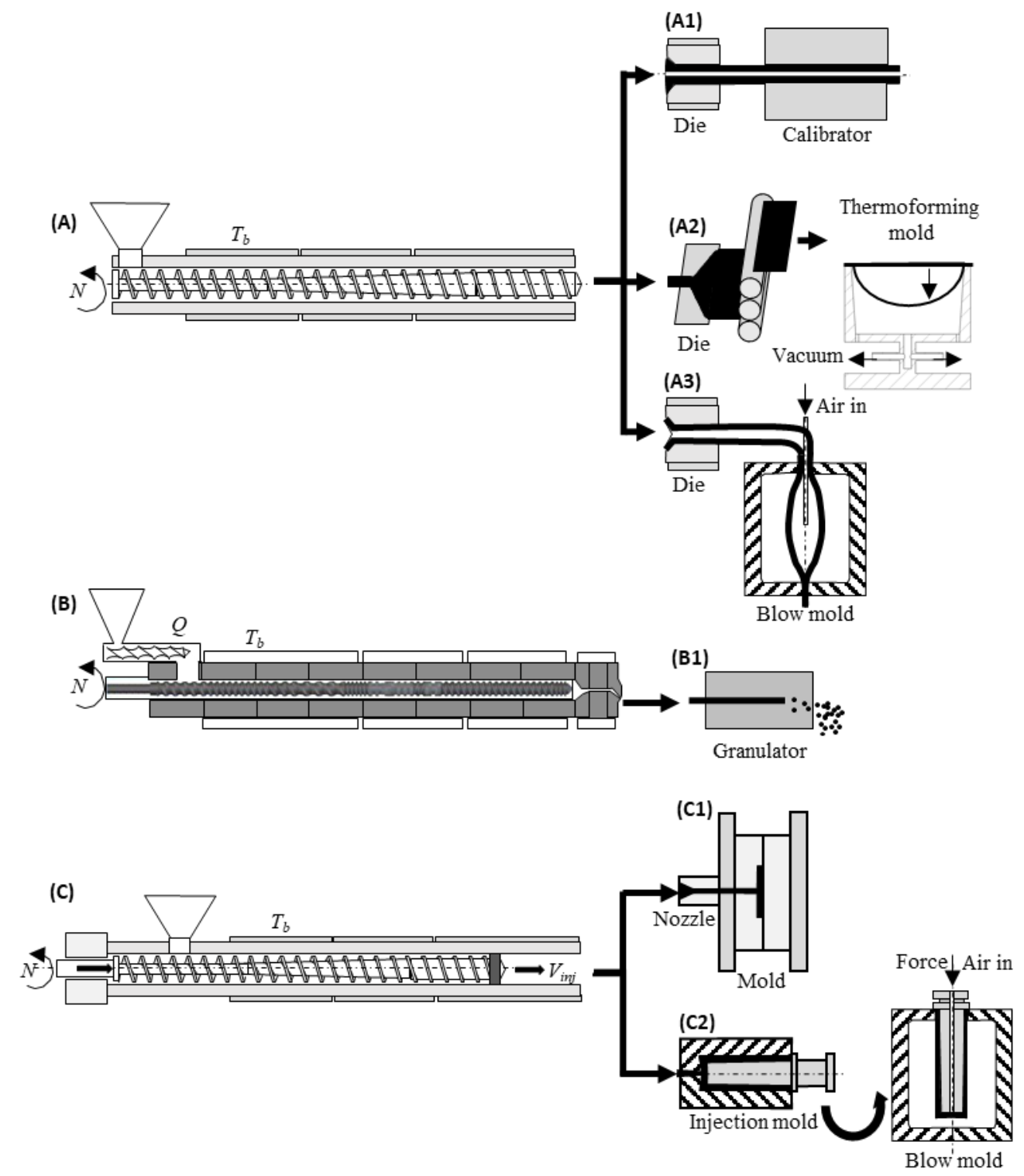

Figure 6. Polymer processing sequences targeted by the present review. (A) single screw extrusion: of profiles (A1), flat film/sheet for thermoforming (A2), extrusion blow molding (A3); (B) corotating twin-screw compounding and pelletizing (B1); (C) injection molding: mold (C2) injection blow molding. Left: plasticizing units; Right: shaping and cooling.

\subsection{Single Screw Extrusion}

This section reviews the previous optimization studies of the plasticating unit of single screw extruders (SSE). The decision variables that have been considered are related with the optimization of the operating conditions (screw speed and barrel temperature profile) and/or of the screw geometry. Conventional and barrier screws, as well as units with a grooved barrel in the feed zone have been studied. Table 1 summarizes the features of the various publications found in the literature. 
Table 1. Previous publications on the optimization of single screw extruders.

\begin{tabular}{|c|c|c|c|c|c|}
\hline $\begin{array}{l}\text { Objective } \\
\text { function }\end{array}$ & $\begin{array}{c}\text { Optimization } \\
\text { Algorithm }\end{array}$ & $\begin{array}{l}\text { Modelling } \\
\text { Approach }\end{array}$ & $\begin{array}{l}\text { Decision } \\
\text { variables }\end{array}$ & $\begin{array}{c}\text { Other } \\
\text { characteristics }\end{array}$ & Authors (year) reference \\
\hline $\mathrm{SO}$ & Direct & $1 \mathrm{D}-\mathrm{A}$ & SD & Step-by-step & Helmy and Parnaby (1976) [38] \\
\hline $\mathrm{SO}$ & Empirical & 1D-A & SD & Grooves & Potente et al. (1992) [39] \\
\hline $\mathrm{SO}$ & ES & $1 \mathrm{D}-\mathrm{A}$ & $\mathrm{OC}+\mathrm{SD}$ & & Worteberg et al. (1994) [40] \\
\hline $\mathrm{SO}$ & Empirical & $1 \mathrm{D}-\mathrm{A}$ & SD & Step-by-step & Chung $(1998,2016)[8,41]$ \\
\hline $\mathrm{SO}$ & Empirical & $1 \mathrm{D}-\mathrm{A}$ & SD & Zone-by-zone & Rauwendaal (1986) [42] \\
\hline $\mathrm{SO}$ & $\mathrm{AL}$ & $3 \mathrm{D}-\mathrm{N}$ & SD & & Altinkaynak (2010), [43] \\
\hline $\mathrm{AP}$ & Empirical & 1D-A & OC & & Potente et al. $(1993,1994,1996)[44,45,46]$ \\
\hline $\mathrm{AP}$ & Regression & $1 \mathrm{D}-\mathrm{A}$ & SD & Statistical & Potente and Zelleröhr (1997) [47] \\
\hline $\mathrm{AP}$ & Regression & $1 \mathrm{D}-\mathrm{A}$ & SD & DOE & Potent and Krell (1997) [48] \\
\hline $\mathrm{AP}(3)$ & Regression & $1 \mathrm{D}-\mathrm{A}$ & $\mathrm{OC}(2)+\mathrm{SD}(1)$ & & Wilczyński et al. $(2001,2003)[49,50]$ \\
\hline $\mathrm{AP}(3)$ & Regression & $1 \mathrm{D}-\mathrm{A}$ & $\mathrm{OC}(2)+\mathrm{SD}(1)$ & & Wilczyński et al. (2004) [51] \\
\hline $\mathrm{AS}(3)$ & Regression & $1 \mathrm{D}-\mathrm{A}$ & SD & & Thibodeau and Lafleur $(2000)[52,53]$ \\
\hline $\mathrm{AS}(2)$ & EA & $1 \mathrm{D}-\mathrm{A}$ & $\mathrm{OC}(2)+\mathrm{SD}(1)$ & & Nastaj and Wilczyński (2018) [54] \\
\hline $\mathrm{AS}(2)$ & EA & $1 \mathrm{D}-\mathrm{A}$ & $\mathrm{OC}(2)+\mathrm{SD}(1)$ & Starve-feed & Nastaj and Wilczyński (2020) [55] \\
\hline $\mathrm{AS}(2)$ & $\mathrm{DE}+\mathrm{PS}$ & Experimental & $\mathrm{OC}(1)$ & Various techniques & Abeykoon et al. (2011, [56] \\
\hline $\mathrm{AS}(4)$ & EA & $2 \mathrm{D}-\mathrm{N}$ & $\mathrm{OC}(4)$ & & Gaspar-Cunha et al. $(1998,[57]$ \\
\hline $\mathrm{AS}(4)+\mathrm{MO}(4)$ & EA & $2 \mathrm{D}-\mathrm{N}$ & $\mathrm{OC}(4)$ & & Covas et al. (1999) [58] \\
\hline $\mathrm{MO}(7)$ & EA & $2 \mathrm{D}-\mathrm{N}$ & $\mathrm{SD}(6)$ & & Gaspar-Cunha et al. (2001) [59] \\
\hline $\mathrm{MO}(5)$ & EA & $2 \mathrm{D}-\mathrm{N}$ & $\mathrm{SD}(5)$ & Barrier screws & Covas et al. (2004) [60] \\
\hline $\mathrm{MO}(2)$ & EA & $2 \mathrm{D}-\mathrm{N}$ & $\mathrm{OC}(4)+\mathrm{SD}(6)$ & Mixing & Domingues at al. (2012) [61] \\
\hline $\mathrm{MO}(5)$ & EA & $2 \mathrm{D}-\mathrm{N}$ & $\mathrm{SD}(4)$ & Barrier screws & Gaspar-Cunha et al. (2006) [62] \\
\hline $\mathrm{MO}(19)$ & EA & 2D-N & $\mathrm{OC}(3)$ & Scale-up & Covas and Gaspar-Cunha (2009) [63] \\
\hline $\mathrm{MO}(9)$ & EA & $2 \mathrm{D}-\mathrm{N}$ & $\mathrm{SD}(4)$ & Scale-up & Gaspar-Cunha and Covas (2014) [64] \\
\hline $\mathrm{MO}(3)$ & EA & $2 \mathrm{D}-\mathrm{N}$ & $\mathrm{SD}(4)$ & Robustness + DM & Denysiuk et al. (2018) [65] \\
\hline $\mathrm{MO}(5)$ & EA & $2 \mathrm{D}-\mathrm{N}$ & $\mathrm{OC}(4)+\mathrm{SD} 86)$ & Innovization & Deb et al. (2014) [66] \\
\hline
\end{tabular}

The earliest attempts to optimize single screw extrusion used statistics, regression, and response surface analyses based on experimental data [35] and computer modelling [36, 37, 38]. Helmy and Parnaby [38] applied a steady-state hill-climbing optimization method, together with an analytical modelling routine, to design screws, this being a good example of the application of traditional optimization methods (see figure 3-A). They implemented an iterative procedure where the required pressure and flow rate at the die, as well as the constraints (e.g., machine dimensions, screw strength and product quality), are initially defined. The search is made considering a single objective (screw power efficiency). Potente et al. [39] used an 1D analytical modelling software to optimize a screw for a grooved barrel extruder, using a trial-and-error procedure. Worteberg et al. [40] employed the same modelling software to develop an expert system to optimize extrusion, but recognized the required intense interaction between process simulation and expert system, in order to create a data base with an adequate dimension, capable to work with variations in operating conditions, material properties and system geometry.

Some authors claimed to design screws "scientifically". Chung $[8,41]$ proposed to design the entire screw through a sequence of steps aiming to match a given output. From a balance between heat conducted and heat generated by viscous dissipation, the depths of the metering and feeding sections were defined. Then, some adjustments were made taking into account practical/empirical rules. Rauwendaal [42] defined the screw geometry by solving the analytical equations pertaining to each functional zone in order to the relevant objectives, such as power consumption and output.

Traditional (and inefficient) methods are still being used to optimize SSE. For example, Altinkaynak [43] developed a full 3D finite element code for the melting and metering 
zones, which was used to optimize the screw pitch and depth of the metering zone. However, since the Augmented Lagrangian method (an algorithm for solving constrained optimization problems) was adopted to maximize output, together with a constraint (the melt temperature at the extruder outlet could not exceed a pre-defined limit), the relevance of the results obtained was very limited. Hence, this work illustrates the need to find a good balance between the use of computationally demanding modelling codes and the optimization method.

Potente and co-authors [44-48] reported one of the first systematic attempts to consider multiple objectives by means of a simple scalar objective function, together with a 1D analytical modelling program. For instance, Potente and co-authors [44, 45, 46] assumed the $\mathrm{M}$-square root ( $\mathrm{M}$ is the number of objectives) of the product of the individual objectives (such as output and length of screw required for melting), to avoid any of them assuming a zero value. However, an empirical procedure was employed to optimize the process. Potente and Zelleröhr [47] optimized the process with a statistical method and a regression analysis, obtaining contour plots for the quality function from a regression analysis to the results generated by the modelling software. Potente and Krell [48] proposed a methodology for screw design involving a DOE (Design of Experiments) and multiple regression. A similar strategy using the STATISTICA software and a 1D analytical process description was adopted by Wilczyński et al. [49, 50]. The barrel temperature, screw speed and screw channel depth in the metering zone were optimized (using a Msquare root of the product of the normalized objectives) in order to maximize mass flow rate and minimize power consumption and melt temperature at the die outlet. Subsequently [51], these results were compared with those obtained using Artificial Neural Networks (ANN) instead of the statistical analysis. It was concluded that the statistical strategy produced better results. Thibodeau and Lafleur [52, 53] adopted a 5-level central composite statistical model to design screws that maximize mixing and minimize melt temperature in the feed zone through a desirability function. The optimum was found on a response surface determined by a $1 \mathrm{D}$ analytical modelling program.

Nastaj and Wilczyński [54] applied EAs to optimize the screw speed and the length of the metering zone that maximize output and minimize mechanical power consumption, with a weighted sum as global objective function. Similarly, the same authors [55] optimized starve fed/flood fed single screw extruders in terms of screw speed, barrel temperature and length of the metering zone, for the same two objectives. They concluded that starve feed extrusion performs better.

Abeykoon et al. [56] compared the performance of differential evolution and particle swarm algorithms, both based on the use of a population of solutions. The aim was to find the barrel set temperatures that minimize the difference between the average melt temperature at the die and the temperature required by the process, as well as the temperature variance at the die. These two objectives were aggregated in a single objective function thru a weighted sum. The melt temperature was evaluated using a static nonlinear polynomial model whose parameters were obtained from experimental data. Data analysis allowed to build a model for evaluating the objectives, while the population based algorithms were used for the optimization.

Gaspar-Cunha et al. [57] analyzed the advantages and shortcomings of implementing an optimization methodology based on the interplay between a modelling package, an objective function, and an EA to solve single screw extrusion problems. The various objectives were taken into account through an aggregation function (the weighted sum) to define the operating conditions (screw speed and barrel temperature profile) that produced the desired output and/or product characteristics. Although the approach was able to find solutions with physical meaning, changing the weights of the aggregation function did not allow to access most of the solutions along the Pareto front, as the algorithm converged to the extremes of the search space. Therefore, multi-objective algorithms seem a better alternative. Indeed, upon applying a MO approach based on EAs to the same SSE problem, the trade-off between four different objectives was established, providing a better understanding of the features of the extrusion system under study [58]. Figure 7 shows 
the two-dimensional Pareto fronts after optimizing the operating conditions of a SSE in order to maximize output and mixing, and minimize the length of screw required for material melting. The aim is to approach the edges, as indicated by the arrows. The best points are those near to the lines in each graph. Nevertheless, during the optimization process it was found that when more than two objectives were considered, most of the solutions were non-dominated. Thus, a new MOEA based on a clustering strategy was developed to select the solutions while maintaining the diversity along the Pareto front. The same MOEA was used to optimize the screw geometry (described by 6 parameters) for the same SSE problem [59], the methodology being sensitive to changes in the design parameters, but obviously dependent on the ability of the modelling routine to provide precise predictions. The approach was extended to the design of Maillefer barrier screws, assuming five design screw parameters and five objectives [60]. Domingues et al. [61] modelled the evolution of the morphology of immiscible liquid-liquid and solid-liquid systems in SSE, and used these data to compute distributive and dispersive mixing indices. These were added as new objective functions to optimize the operating conditions and screw geometry using the same MOEA. Subsequently, a modified strategy was adopted to optimize all together conventional and Maillefer barrier screws [62]. A structured chromosome representation was adopted, in which various parts of the chromosome represent the same variables and the genotype representation is based on a hierarchy (i.e., one of the decision variables is a flag indicating the type of screw). The results showed that different regions of the Pareto front are attained by the two screw types.

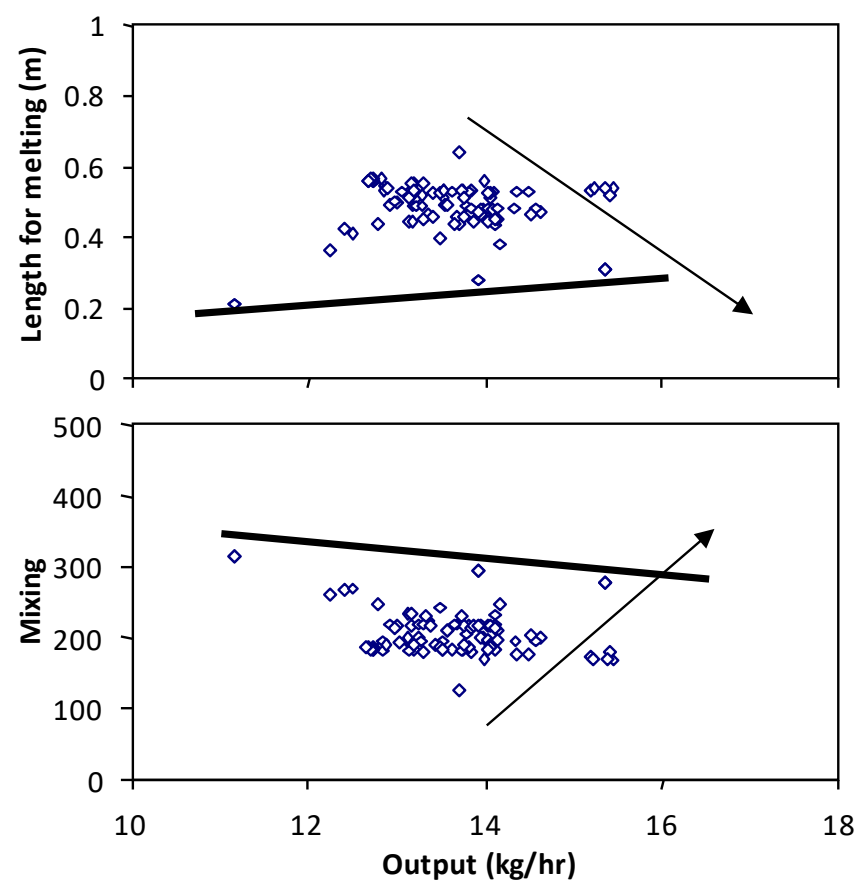

Figure 7. Pareto curves after optimization of the operating conditions of a SSE, in order to maximize output and mixing and minimize the length of screw required for melting.

Scale-up in SSE often consists in finding the geometry and/or the operating conditions of a target extruder (in general, of production size) in order to obtain materials or products with the same characteristics of those developed with existing equipment (commonly, a laboratory extruder). This should require that flow and heat transfer at the two scales are similar, but the problem is difficult to solve as changes in scale affect differently the various process parameters. Covas and Gaspar-Cunha [63] approached scale-up as a multiobjective optimization problem, where the aim is to minimize the differences in performance between extruders of different sizes while satisfying simultaneously several objectives. Screw speed and barrel temperatures in three zones were initially assumed as 
decision variables. Subsequently, the same methodology was applied to screw design, considering four screw geometrical parameters and nine objectives [64].

Robustness and decision making strategies have also been included in the solution of SSE problems [65]. In this way, it becomes possible to focus the search on solutions that converge to regions where the preference was defined either by the relative importance of the objectives, or by considering the robustness of solutions against perturbations in the design variables. Deb et al. [66] proposed an "innovization" methodology to capture relationships between the relevant process parameters (i.e., the decision variables) and the objectives from the final results of a multi-objective optimization algorithm. After applying a MOEA, the optimal trade-off solutions are analyzed and the interactions between the parameters are obtained automatically. The procedure was applied to an SSE problem, a set of rules relating the relevant decision variables with the objectives for each case studied being established.

\subsection{Twin-Screw Extrusion}

As illustrated in Figure 8, optimization of twin-screw extruders (TSE) may involve: i) the definition of the operating conditions ( $N$ - screw speed, $Q$ - feed-rate and $T_{b}$ - barrel temperature profile); ii) the determination of the geometry of individual screw elements; and/or iii) the determination of the screw configuration, i.e., finding the best location along the screw axis of existing screw elements). These problems arise within the context of compounding, reactive extrusion, extrusion, or scale-up, and can involve co-rotating or counter-rotating intermeshing twin-screw extruders. Table 1 summarizes the features of the previous studies on these topics.

As with SSE, co-rotating twin-screw extruders were initially optimized using empirical approaches based on experimental and computational data. Potente and co-authors $[67,68]$ developed SIGMA, a 1D modelling software, but details on the optimization method, including design variables and objectives, were not given. The results achieved seem to have been based on a trial-and-error procedure. Vainio et al. [69] investigated experimentally different screw profiles for the preparation of an uncompatibilized immiscible PA6/PP blend, with the aim of optimizing the screw configuration. Although the process parameters influencing mixing were identified, no systematic optimization method was offered. Berzin et al. [70] optimized graphically the cationization of wheat starch in a laboratory extruder in terms of screw configuration and operating conditions, taking into account geometrical and process constraints, with the aim of scaling-up the results to a larger industrial extruder. Five different screw configurations were analyzed, assuming the minimization of the specific mechanical energy and the maximization of the reaction efficiency. The scale-up procedure used the same type of data for screws geometrically similar to those studied for the smaller extruder. 


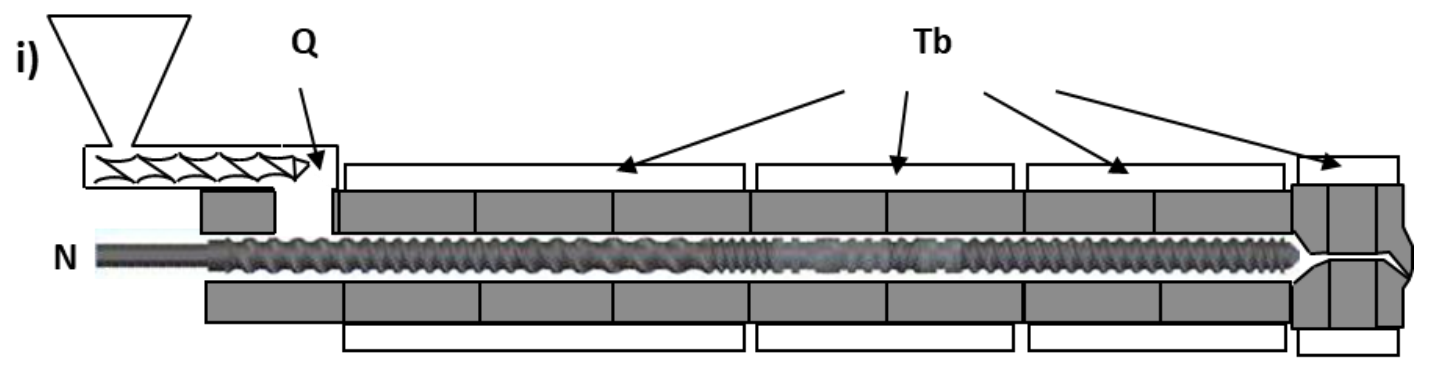

ii)
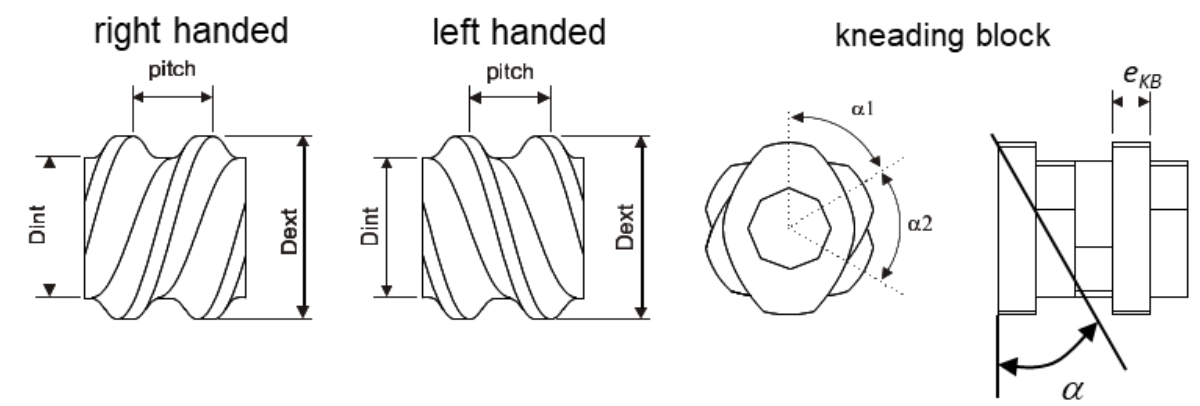

iii)

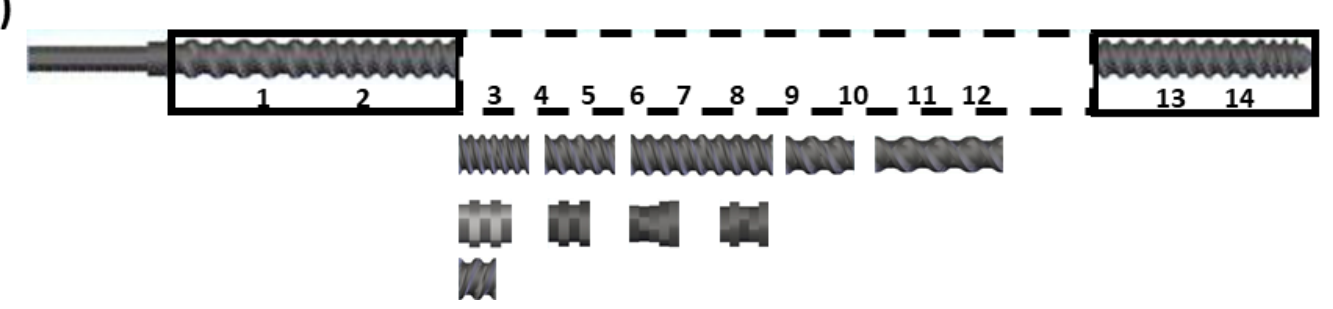

Figure 8. Optimization of co-rotating twin-screw extruders (TSE): i) operating conditions, screw speed $(\mathrm{N})$, feed rate $(\mathrm{Q})$ and barrel and die set temperatures $(\mathrm{Tb})$; ii) geometry of individual screw elements; iii) position of a set of individual screw elements ( 5 conveying elements, 3 kneading blocks and 1 left handed element) along the screw shaft.

Table 2. Previous publications on the optimization of twin-screw extruders.

\begin{tabular}{|c|c|c|c|c|c|}
\hline $\begin{array}{c}\text { Objective } \\
\text { function }\end{array}$ & $\begin{array}{c}\text { Optimization } \\
\text { Algorithm } \\
\end{array}$ & $\begin{array}{l}\text { Modelling } \\
\text { Approach }\end{array}$ & $\begin{array}{c}\text { Decision } \\
\text { variables }\end{array}$ & $\begin{array}{c}\text { Other } \\
\text { characteristics }\end{array}$ & Authors (year) reference \\
\hline Not defined & Empirical & $1 \mathrm{D}-\mathrm{A}$ & Not defined & & Potente et al. $(1994,1999)[67,68]$ \\
\hline $\mathrm{SO}$ & Empirical & Experimental & Not-defined & Mixing & Vainio et al. (1995) [69] \\
\hline $\mathrm{SO}(2)$ & Regression & 1D-Ludovic & $\mathrm{OC}(3)+\mathrm{SD}(1)$ & Reactive Extrusion & Berzin et al. (2007) [70] \\
\hline $\mathrm{SO}$ & Regression & Experimental & $\mathrm{OC}(2)$ & Counter-rotating & Maridass and Gupta $(2004,[71]$ \\
\hline $\mathrm{SO}(2)$ & Regression & Experimental & $\mathrm{OC}$ & Reactive Extrusion & Ulitzsh et al. (2020) [72] \\
\hline $\mathrm{SO}(2)$ & Regression & Experimental & $\mathrm{OC}(2)$ & Scale-up & Fukuda et al. (2015) [73] \\
\hline $\mathrm{AP}(3)$ & Gradient & $1 \mathrm{D}-\mathrm{A}$ & $\mathrm{SD}(2)$ & Conv. elements & Potente and Thümen(2006) [74] \\
\hline $\mathrm{AS}(2)$ & EA & 2D-numerical & $\mathrm{OC}(1)+\mathrm{SD}(1)$ & Reactive Extrusion & Zhang et al. (2015) [75] \\
\hline $\mathrm{AS}+\mathrm{MO}(6)$ & EA & 1D-Ludovic & $\mathrm{OC}(4)$ & & Gaspar-Cunha et al. (2002) [76] \\
\hline $\mathrm{MO}(7+2)$ & EA & 1D-Ludovic & $\mathrm{OC}(4)+\mathrm{SC}(10)$ & Reactive Extrusion & Gaspar-Cunha et al. (2005) [78] \\
\hline $\mathrm{MO}(5)(7)$ & EA & 1D-Ludovic & $\mathrm{SD}(4)+\mathrm{SC}(10)$ & Robustness & Covas et al. (2004) [60] \\
\hline $\mathrm{MO}(3)$ & SLS & 2D-FD & $\mathrm{SC}(14)$ & & Teixeira et al. (2011) [80] \\
\hline $\mathrm{MO}(3)$ & EA+ACO+SLS+TPLS & 2D-FD & SC(14) & & Teixeira et al. (2012) [81] \\
\hline $\mathrm{MO}(3)$ & ACO+TPLS & 2D-FD & SC(14) & & Teixeira et al. (2014) [82] \\
\hline $\mathrm{MO}(3)$ & EA & 1D-Ludovic & $\mathrm{OC}(1)+\mathrm{SC}(14)$ & Reactive Extrusion & Teixeira et al. (2011) [83] \\
\hline $\mathrm{MO}(3)$ & EA & 2D-FD & $\mathrm{SD}(1)+\mathrm{SC}(8)$ & Scale-up & Covas et al. (2011) [84] \\
\hline
\end{tabular}

Various authors adopted statistical methods for TSE optimization. The analysis applied by Maridass and Gupta [71] was based on experimental data on the recycling of natural rubber vulcanizates in a counter rotating twin screw extruder. The aim was to find 
the barrel temperature and screw speed that maximized the properties of the material obtained. For that purpose, the contour plots obtained were analyzed visually. Ulitzsch $e t$ al. [72] selected a response surface methodology to optimize the synthesis of vinyltrimethoxysilane-grafted ethylene-octene-copolymer using experimental data. Five process parameters and their interactions were optimized, in order to maximize both the grafting degree and efficiency. Second-order interaction effects existed, making this process difficult to control with such a simple optimization methodology. Fukuda et al. [73] used a DOE to analyzed separately two different scale-up rules, one based on the volumetric flow rate, the other related to dispersive mixing, with the aim of optimizing the operating conditions of the target extruder.

Potente and Thümen [74] applied a gradient method to optimize the radial and flight clearances of conveying screw elements, in order to maximize the pressure gradient and minimize the temperature gradient and power consumption.

Zhang et al. [75] employed a single objective EA to optimize free radical bulk polymerization, with the aim of defining the barrel temperature and screw length that maximize both monomer conversion and monomer conversion per unit energy consumption. A weighted sum took into account the two objectives. A weighted sum and a MOEA were adopted to set the operating conditions of three extruders with different screw configurations [76], while using the Ludovic software [77] to evaluate the objective functions.

When optimizing operating conditions, or the geometry of individual screw elements, the characteristics of these tasks are identical to those of equivalent SSE problems, since the decision variables to optimize vary continuously in the search space. However, defining the best location of screw elements along the screw shaft is a discrete and combinatory problem. Gaspar-Cunha et al. [78] used a modified MOEA to define the most adequate location of a pre-selected set of screw elements (denoted as screw configuration problem, SC). An analogy was made with the traveling salesman problem, or sequencing problem in operations research, with the cities being the screw elements that must be covered sequentially by the traveling salesman in order to maximize a prescribed performance. Within the obvious limitations of the exercise, the results were validated experimentally and the methodology was also applied to $\varepsilon$-caprolactam polymerization via reactive extrusion. Later, the robustness of the solutions, considering changes in the value of the decision variables, was also taken into account [60]. An alternative approach using Stochastic Local Search (SLS) algorithms to tackle the SC problem was also attempted [79]. An efficient single-objective iterative improvement strategy, based on various neighborhood structures, neighborhood search strategies, and neighborhood restrictions, was proposed, whereby the algorithms were embedded into a variation of a bi-objective twophase local search (TPLS) framework. The results were compared to those obtained by the previous MOEA, evidencing a higher quality approximation to the Pareto front, with a faster convergence. Process modelling contained of a global plasticating treatment co-rotating twin screw extrusion [80]. Given the good results obtained, Teixeira et al. [81] solved the SC problem through the hybridization of different local search procedures, including Pareto local search and TPLS algorithms, with two different population-based algorithms, a MOEA and a Multi-Objective Ant Colony (MOACO). This approach outperformed the other algorithms studied and their combinations. With the aim of exploring the full potential of the hybrid algorithm, the influence of the MOACO algorithm parameters was investigated, and the results obtained were compared with those of MOEA and TPLS algorithms [82]. It was concluded that the hybridization of the MOACO algorithm has a significant potential for solving the SC problem.

Teixeira et al. [83] adopted a MOEA algorithm to solve the SC problem for starch cationization by reactive extrusion, aiming at the minimization of the specific mechanical energy and the maximization of output and reaction conversion. As far as scale-up in TSE is concerned, Gaspar-Cunha and Covas [84] employed a multi-objective optimization strategy to define the geometry (location of eight screw elements) and operating conditions of the target extruder that minimized the differences in viscous dissipation, specific mechanical energy and average strain between the target and reference machines. 


\subsection{Dies and Calibrators}

Extrusion dies aim at converting the circular flow at the outlet of the extruder into a flow with a specific cross-section (to produce film/sheet, pipes, profiles, etc). The latter may not correspond to the actual product cross-section/dimensions, as the die geometry must compensate for all the shape/dimensional changes of the extrudate along the extrusion line. As a matter of fact, due to its viscoelastic nature, the extrudate will swell progressively as it leaves the die, but this might be partially/totally offset by the draw down created by the haul-off. During cooling, thickness differences may arise in the cross-section due to gravity flow, and the extrudate will shrink and might distort due to buoyancy forces in a water tank. Thus, not only extrusion dies are built in such a way that they attempt to anticipate subsequent changes in the shape of the extrudate, they allow for some local adjustments in the channel geometry. Also, whenever possible, the external contour of the extrudate is corrected prior to cooling by means of a calibrator.

Extrusion dies usually comprise an adapter, which converts the circular flow from the extruder into the required channel shape for extrusion, and a parallel zone with constant cross-section, which allows for some macromolecular relaxation. The ensemble adapter/parallel zone should be designed in such a way that the velocity and the residence time of all the individual melt streams in the cross-section are uniform. To ensure this, and despite of the wide variety of extruded shapes, there are generally three approaches to design the adapter:

i) using a manifold, i.e., use a larger channel upstream to distribute the flow transversally, prior to its progress downstream. The die geometry is such that a central flow stream has a shorter path in the manifold and a longer path in the shallower parallel zone, while the reverse occurs for a flow stream near to the edges. This approach is frequently adopted for the production of cast film and sheet, wire insulation and extrusion blow molding.

ii) using a cylindrical mandrel to convert the circular flow from the extruder into an annular flow. Since the classical torpedo-type solution with its supports (known as spider legs) creates unbalanced flow and strong welding lines, it was progressively replaced by basket-type dies and spiral mandrel dies. The mandrels of the latter are designed in such a way that the flow from the extruder is divided into individual melts which feed helical channels with decreasing depth along their length in the mandrel. Thus, the helical flow is gradually converted into an axial annular flow.

iii) using an adapter to change gradually from the inlet circular channel into the desired cross-section. The design of dies for hollow profiles, or for profiles containing thickness differences in their cross-section is particularly challenging.

Rakos and Sebastian [85] proposed an empirical optimization procedure to define the geometry of different types of dies using a numerical modelling code, but no details were given concerning the objectives and design variables. In the following sections, each type of die is studied separately

\subsubsection{Manifold Dies}

Matsubara $[86,87]$ solved the analytical flow modelling equations in order to a major design variable (the variation along the length of the manifold radius) of a coat hanger die that assured uniform flow rate and residence time across the width, and extended the methodology to T-dies [88, 89]. Table 3 shows that the design of manifold dies as an optimization problem was carried out using a single objective function, and that as optimization procedure empirical methods, regression analyses, sequential quadratic programing, gradient techniques, or evolutionary algorithms were adopted. 
Table 3. Previous publications on the optimization of manifold dies (manifold type: CH- Coat Hanger, TCH- Tapered Coat Hanger, Blow - blow molding)

\begin{tabular}{|c|c|c|c|c|c|}
\hline $\begin{array}{l}\text { Objective } \\
\text { function }\end{array}$ & $\begin{array}{c}\text { Optimization } \\
\text { Algorithm }\end{array}$ & $\begin{array}{l}\text { Modelling } \\
\text { Approach }\end{array}$ & $\begin{array}{l}\text { Decision } \\
\text { variables }\end{array}$ & $\begin{array}{c}\text { Other } \\
\text { characteristics }\end{array}$ & Authors (year) reference \\
\hline Not defined & Empirical & $1 \mathrm{D}-\mathrm{A}$ & DG(?) & Various dies & Rakos and Sebastian (1990) [85] \\
\hline $\mathrm{SO}$ & Empirical & $1 \mathrm{D}-\mathrm{A}$ & $\mathrm{DG}(1)$ & $\mathrm{CH}$ & Matsubara $(1979,1980)[86,87]$ \\
\hline $\mathrm{SO}$ & Empirical & $1 \mathrm{D}-\mathrm{A}$ & $\mathrm{DG}(1)$ & T-die & Matsubara $(1980,1988)[88,89]$ \\
\hline $\mathrm{SO}$ & Empirical & $1 \mathrm{D}-\mathrm{A}$ & $\mathrm{DG}(3)$ & $\mathrm{CH}$ & Winter and Fritz (1986) [90] \\
\hline $\mathrm{SO}$ & Empirical & $3 \mathrm{D}-\mathrm{N}$ & $\mathrm{DG}(3)$ & $\mathrm{CH}$ & Liu et al. $(1988,1994)[91]$ \\
\hline SO & Empirical & $3 \mathrm{D}-\mathrm{N}$ & $\mathrm{DG}(4)$ & $\mathrm{TCH}, 2$ cavities & Lee and Liu (1989) [92] \\
\hline SO & Empirical & $3 \mathrm{D}-\mathrm{N}$ & DG(3) & $\mathrm{CH}$ & Liu et al. $(1988,1994)[93]$ \\
\hline $\mathrm{SO}$ & Empirical & $3 \mathrm{D}-\mathrm{N}$ & $\mathrm{DG}(4)$ & $\mathrm{TCH}$ & Yu and Liu (1998) [94] \\
\hline $\mathrm{SO}$ & Empirical & $3 \mathrm{D}-\mathrm{N}$ & DG(3) & $\mathrm{CH}$ & $\mathrm{Na}$ and Kim (1995) [95] \\
\hline $\mathrm{SO}$ & Empirical & $2 \mathrm{D}-\mathrm{N}$ & $\mathrm{DG}(2)$ & $\mathrm{CH}$ & Huang et al. (2004) [96] \\
\hline SO & Regression & $1 \mathrm{D}-\mathrm{A}$ & $\mathrm{OC}(1)+\mathrm{DG}(3)$ & $\mathrm{CH}$ & Chen et al. (1997) [97] \\
\hline $\mathrm{SO}$ & Regression & $3 \mathrm{D}-\mathrm{N}$ & $\mathrm{DG}(5)$ & $\mathrm{CH}$ & Razeghiyadaki et al. $(2020,2021)[98,99]$ \\
\hline $\mathrm{SO}$ & SQP + Regression & $3 \mathrm{D}-\mathrm{N}$ & $\mathrm{DG}(1)$ & $\mathrm{CH}$ & Lebaal et al. (2006) [100] \\
\hline $\mathrm{SO}$ & SQP + Regression & $3 \mathrm{D}-\mathrm{N}$ & DG(4) & $\mathrm{CH}$ & Lebaal et al. (2009) [101] \\
\hline SO & SQP + Regression & $3 \mathrm{D}-\mathrm{N}$ & $\mathrm{OC}(3)+\mathrm{DG}(1)$ & $\mathrm{CH}$ & Lebaal et al. (2010) [102] \\
\hline $\mathrm{SO}$ & SQP + Regression & $3 \mathrm{D}-\mathrm{N}$ & $\mathrm{DG}(4)$ & $\mathrm{CH}$ (wire) & Lebaal et al. (2012) [103] \\
\hline $\mathrm{SO}$ & Gradient & $3 \mathrm{D}-\mathrm{N}$ & $\mathrm{DG}(2)$ & $\mathrm{CH}$ & Smith et al. $(1998,1998)[104,105]$ \\
\hline SO & Gradient & $3 \mathrm{D}-\mathrm{N}$ & $\mathrm{OC}(1)+\mathrm{DG}(2)$ & $\mathrm{CH}$ & Smith (2003) [106] \\
\hline $\mathrm{SO}$ & Gradient & $3 \mathrm{D}-\mathrm{N}$ & DG(811) & $\mathrm{CH}$, Robustness & Smith (2003) [107] \\
\hline $\mathrm{SO}$ & Gradient & $3 \mathrm{D}-\mathrm{N}$ & $\mathrm{DG}(9)$ & $\mathrm{CH}$ & Sun and Gupta (2004) [108] \\
\hline $\mathrm{SO}$ & Gradient & $3 \mathrm{D}-\mathrm{N}$ & DG(5) & $\mathrm{CH}$, Restrictor & Bates et al. (2003) [109] \\
\hline $\mathrm{SO}$ & $\begin{array}{c}\text { Regression+ } \\
\text { Gradient+EA }\end{array}$ & $3 \mathrm{D}-\mathrm{N}$ & DG(5) & $\mathrm{CH}$, Restrictor & Siens et al. (2006) [110] \\
\hline $\mathrm{SO}$ & EA & $3 \mathrm{D}-\mathrm{N}$ & DG(n) & $\mathrm{CH}$ & Michaeli and Kaul (2004) [11] \\
\hline $\mathrm{SO}$ & EA & $3 \mathrm{D}-\mathrm{N}$ & $\mathrm{DG}(2)$ & $\mathrm{CH}$ & Meng and Zhao (2011) [112] \\
\hline $\mathrm{SO}$ & EA & $3 \mathrm{D}-\mathrm{N}$ & $\mathrm{DG}(4)$ & Slot die & Sun and Wang (2010) [113] \\
\hline $\mathrm{SO}$ & EA & $3 \mathrm{D}-\mathrm{N}$ & $\mathrm{DG}(2)$ & Blow: 2-CH & Meng et al. $(2009,2012)[114,115]$ \\
\hline $\mathrm{AS}(2)$ & Regression & $3 \mathrm{D}-\mathrm{N}$ & DG(3) & $\mathrm{CH}$ & Han and Wang (2012) [116] \\
\hline $\mathrm{AS}(\mathrm{n})$ & Gradient & $3 \mathrm{D}-\mathrm{N}$ & $\mathrm{OC}(1)+\mathrm{DG}(2)$ & $\mathrm{CH}$, Robustness & Smith and Wang (2004) [117] \\
\hline $\mathrm{AS}(\mathrm{n})$ & Gradient & $3 \mathrm{D}-\mathrm{N}$ & $\mathrm{OC}(1)+\mathrm{DG}(2)$ & $\mathrm{CH}$ & Smith and Wang (2005) [118] \\
\hline $\mathrm{AS}(\mathrm{n})$ & SQP & $3 \mathrm{D}-\mathrm{N}$ & $\mathrm{OC}(1)+\mathrm{DG}(2)$ & $\mathrm{CH}$ & Wang and Smith $(2006)[119,120]$ \\
\hline $\mathrm{AS}(3)$ & EA & $3 \mathrm{D}-\mathrm{N}$ & $\mathrm{OC}()+\mathrm{DG}()$ & $\mathrm{CH}$ & Zhang et al. (2020) [121] \\
\hline $\mathrm{MO}(2)$ & DOE, RSM, EA & $3 \mathrm{D}-\mathrm{N}$ & $\mathrm{DG}(3 / 8 / 12)$ & $\mathrm{CH}$ & Lee et al. (2015) [122] \\
\hline $\mathrm{MO}(2)$ & EA & $3 \mathrm{D}-\mathrm{N}$ & DG(3) & $\mathrm{CH}$ & Han and Wang (2012) [123] \\
\hline $\begin{array}{c}\mathrm{AS}(2) \& \\
\mathrm{MO}(2)\end{array}$ & Regression + EA & $3 \mathrm{D}-\mathrm{N}$ & DG(1) & Blow: 2-CH & Han and Wang (2014) [124] \\
\hline
\end{tabular}

Winter and Fritz [90] recommended the use of a specific design procedure for a coat hanger die, taking into account uniformity of the exit velocity and average residence time, regardless of flow rate or polymer viscosity, and considering separation of the flows. The geometry of dies with a square and circular manifold and constant thickness of the parallel section was defined, in which the design variables were the width or the diameter of the manifold, as a function of its length, and the height of the parallel section.

Liu et al. [91] developed a method to optimize coat hanger dies with non-circular manifold, to avoid dead spots in the transition to the parallel zone. The aim was to define the geometries of the manifold and parallel zone in order to deliver uniform flow, while 
keeping uniform residential time distribution for different polymers and operating conditions. A numerical modelling program was used to evaluate the solutions. The same empirical strategy was used by Lee and Liu [92] to design a coat-hanger die with a linearly-tapered inner cavity and a straight outer cavity, but taking into account inertial, gravitational, and viscous effects. Later, Liu et al [93] and $\mathrm{Yu}$ and Liu [94] proposed a unified lubrication approximation to model the polymer flow inside the die with the aim of designing the same coat-hanger die [93] and a tapered coat-hanger die [94].

$\mathrm{Na}$ and Kim[95] applied an empirical approach to design linearly tapered coathanger dies with circular manifold (in terms of slot thickness, manifold angle and land length) with the aim of obtaining uniform flow rate distribution at the die exit in the transverse direction, using a 3D finite element modelling code. Even recently, a simple empirical approach was used by Huang et al. [96] to design coat hanger dies that maximize the uniformity of the velocity distribution at the die exit defining as decision variables the manifold radius and angle and slit height.

The application of regression techniques, based, for example, in Taguchi methods, enabled the development of more systematic optimization approaches. This is the case of Chen et al. [97], who investigated the effect of material rheology, gap thickness, manifold angle, and flow rate, on the thickness uniformity of coat hanger dies. The Taguchi method was used to optimize the geometry of dies with different widths, the solutions being evaluated with an analytical model, and flow rate was also appended as design variable. Recently, Razeghiyadaki et al. $[98,99]$ used a response surface method to optimize the geometry of a coat hanger die in order to obtain uniform velocity at the die lips. The response surface was generated from computations using a commercial package, and a central composite DOE defined the conditions for the calculations. A spline curve was used to outline the geometry using five variables (depth and the width of the die and three nodes of the spline). The optimization involved minimizing the quadratic function obtained. Lebaal et al. [100] determined the geometry of a coat-hanger die using a global response surface method with Kriging interpolation (a regression technique), and Sequential Quadratic Programming (SQP) to minimize the global difference between the local velocities at the die exit and the average value, assuming as decision variable the depth of the distribution channel, and as restriction the pressure required by the flow. Later, four decision variables were considered, namely the depth and the opening of the channel repartition, the gap, and the height of the relaxation zone [101]. The same methodology was applied to define the depth of the distribution channel and the operating conditions [102], as well as to design a wire coat hanger based on the same flow balance principle [103]. It is important to note that SQP requires that the objective function and the constraints are twice differentiable, which was possible in this case because the objective function and the constraints were defined by regression prior to the application of SQP.

Smith et al. [104] proposed a systematic optimization methodology combining process modeling, a design sensitivity analysis (using both direct and adjoint methods), and optimization based on a gradient technique. The aim was to keep the non-uniformity of the velocity profile across the die exit below a certain level, and to minimize pressure drop, i.e., to achieve product homogeneity with minimal processing cost. The design variables were the length of the parallel zone and the cross section of the flow channel. The residence time in the die was considered subsequently [105]. Then, with the aim of minimizing the die length and to satisfy constraints related to uniform residence time and exit velocity, the inlet pressure, the manifold height and the shape of the parallel zone were taken as variables [106]. Also, to determine the geometry of a sheet die that will best accommodate a range of operating conditions, Smith [107] optimized 811 half-height design variables that describe the die cavity thickness distribution for an example where the inlet and outlet die half-heights are fixed. Sun and Gupta [108] applied a gradient quadratic penalty method to define the geometry of a coat hanger die (using nine decision variables), that minimizes the velocity variation across the die exit without excessively increasing the pressure drop. The penalty method consisted in adding a burden to the objective function for surpassing a pressure drop threshold. Bates et al. [109] applied a gradient optimization 
method to determine the optimum geometrical profiles of a restrictor (choker bar) necessary to obtain a uniform flow distribution of a slit die to be used in a range of applications involving three materials with varying degrees of shear thinning, each at a high and a low flow rate. The restrictor was optimized considering the height of five points along half the width of the die. Later, this study was extended to include regression and EA optimization algorithms [110].

A single objective EA was used by Michaeli and Kaul [111] to optimize a T-shaped manifold, in order to minimize the standard deviation of the local velocities at the die exit, the decision variables being a few points in the mesh that defined the flow path. The same optimization strategy was applied to define the geometry of a coat hanger die taking as design variables two parameters related with the radius of the manifold and the height of the parallel zone [112]. Also using a single objective EA, Sun and Wang [113] optimized four geometrical parameters of the manifold. The aim was to minimize the stagnation temperature (a combination of static and kinetic temperatures), and the solutions were evaluated using a 3D numerical commercial modeling code. Meng et al. [114, 115] designed a double coat hanger die with a manifold of quadratic geometry in order to distribute uniformly the melt across a large width. A single objective EA was selected to define the gap and the manifold angle.

Several authors recognized the need to take in several objectives, hence using aggregation functions (e.g., weighted sum) together with single objective optimization algorithms. Han and Wang [116] applied a regression technique (based on an orthogonal array design) to determine the manifold angle and gap height of a coat-hanger die that minimize the variation of the outlet velocity and the residence time, using a 3D numerical modeling code. The same optimization methodology (see also [104]) was used to include the effect of the variability of the set temperature or of material properties, i.e., a robustness analysis. In this case, the objective function was the weight sum of the inlet pressures for each flow condition that are induced by changes in temperature and/or material properties [117, 118]. An arbitrary gap height distribution in the manifold and different polymer rheological models were also added [118]. Wang and Smith [119, 120] solved the same problem using SQP. Zhang et al. [121] optimized the geometry and operating conditions of a coat hanger die using a single objective EA consisting of the weighted sum of three objectives (minimization of the mechanical deformation of the die, of the pressure drop and of the variation of the outlet velocity). The solutions to be evaluated were obtained through the application of a DOE, from which a regression model was obtained to be used by the EA.

Only recently MO optimization methods have been applied to the definition of the die geometry. Lee et al. [122] evaluated the performance of different optimization strategies (comprising a design of experiments, the response surface model and two different MOEAs) for the delineation of the geometry of a coat hanger die. The latter was divided in sectors that resulted in three case studies involving the definition of three, eight and twelve design variables, respectively. In parallel, two objectives were selected, minimization of the total pressure drop and maximization of a flow uniformity parameter, which were evaluated using a commercial 3D modeling software. Considering simultaneously these two objectives, Han and Wang [123] used a MOEA to optimize the same geometrical parameters, taking as starting point the geometry of a previously optimized die [116]. Later, the same authors [124] optimized a double coat-hanger die with a quadratic geometry manifold using identical optimization techniques (regression and MOEA).

\subsubsection{Mandrel Dies}

Table 4 identifies the previous studies concerning the optimization of mandrel dies. Huang [125] proposed a strategy with two steps to optimize the geometry of a spiral mandrel die (that can be utilized for the extrusion of pipes and blown films). The Taguchi method was used to define a set of geometries able to assess the flow balance principle, then this set of geometries were evaluated iteratively taking into account total pressure drop, degree of mixing and residence time distribution. It was concluded that the best solution to use in real practice results from a balance between the different objectives, 
hence a multi-objective strategy must be pursued. Mu et al. [126] adopted a MOEA to optimize the geometry of an annular die, aiming at minimizing local differences in outlet velocity and minimizing the swell ratio, while restricting the shear stress to a critical value that guaranteed steady extrusion. An ANN, trained with 3D numerical modelling results, was used to evaluate the solutions, whilst the decision variables were the channel contraction angle, the flow gap and the relative length of the parallel zone.

Table 4. Previous publications on the optimization of mandrel.

\begin{tabular}{|c|c|c|c|c|c|}
\hline $\begin{array}{l}\text { Objective } \\
\text { function }\end{array}$ & $\begin{array}{c}\text { Optimization } \\
\text { Algorithm }\end{array}$ & $\begin{array}{l}\text { Modelling } \\
\text { Approach }\end{array}$ & $\begin{array}{l}\text { Decision } \\
\text { variables }\end{array}$ & $\begin{array}{c}\text { Other } \\
\text { characteristics }\end{array}$ & Authors (year) reference \\
\hline $\mathrm{SO}$ & Regression & $2 \mathrm{D}-\mathrm{N}$ & $\mathrm{DG}(4)$ & & Huang (1998) [125] \\
\hline $\mathrm{MO}(2)$ & EA & 3D-N + ANN & $\mathrm{DG}(3)$ & & Mu et al. (2010) [126] \\
\hline
\end{tabular}

\subsubsection{Profile Dies}

Two main approaches (not necessarily exclusive) have been generally adopted for the design of profile dies (see Table 5 for a summary of the previous studies published): optimization of the flow balance at the die exit, and correction of the shape/dimensions of the die exit for the effect of post-extrusion extrudate-swell (this is sometimes denoted as the Inverse Extrusion Problem (IEP) [127]. According to Pittman [128], the design of profile dies should encompass the following aspects: i) consider as much as possible the thermomechanical phenomena, such as an appropriate rheological description and kinematics, eventual wall slip conditions, extrusion instabilities, material residence time and degradation, extrudate swell, draw-down and thermal effects; ii) select the best strategy, e.g. flow balancing, streamlined channels, avoiding-cross-flow, using flow separators and designing for extrudate swell; iii) formulate clearly the optimization in terms of objective function, constraints, decision variables, algorithms and optimization strategies; iv) perform a clear geometry and mesh parameterization.

Legat and Marchal [127] designed a square die by solving the IEP for the die channel shape given the extrudate geometry, based on an implicit formulation. Tran-Cong and Phan-Thien [129] proposed an empirical optimization method to take into account the effect of extrudate-swell on die design. Flow modeling used the boundary element method and the free surface was modelled based on particle path lines that were optimized at every iteration. Also through a trial-and-error empirical approach, Hurez et al. [130] optimized the lengths of the die land channels using analytical flow modelling. Three empirical strategies based on cross flow minimization were utilized by Švábík et al. [131] to achieve flow balancing by varying the die land length. However, these methods are only able to deal with simple dies. With the aim of solving the IEP, Gifford [132] discussed the concept of target profile, i.e., the final profile to be obtained after the extrudate-swell, and how to deal with the free surface using surface particles that must fit the target profile. Rezaei et al. [133] optimized the length of the die lands of a profile die using an empirical scheme based on sensitivity analysis in order to balance the flow at die exit.

One of the first systematic optimization approaches was made by Coupez et al. [134], who adopted the simplex method to optimize the geometrical parameters of a profile die in terms of flow balancing, based on 3D numerical modelling, but with unclear decision variables. Ready and Schaub [135] used of a regression optimization method based on a response surface methodology with the results obtained by an adaptive 3D numerical method, and defining as decision variables the corner positions of macro-blocks located in the numerical mesh. An optimization approach based on the gradient-free method (specifically, bound optimization by quadratic approximation) was applied to manifold and profile dies [136] The method uses a regression approach based on a quadratic response surface obtained from the modeling calculations. Spline lines approximate the domain boundary, the design variables corresponding to the weights and locations of the 22 control points that define the splines. The objective function was the variance of the local maximal velocity as compared to the average maximal velocity over all die sections. Based on the same optimization framework, Pauli et al. [137] considered that a good die design 
must also attain a homogeneous extrudate-swell across the die exit, and thus applied the two objectives simultaneously to a U-shape profile using $19 \times 9$ control points.

Table 5. Previous publications on the optimization of profile dies (KP - key points (see text); MP - mesh parameterization; GP geometry parameterization).

\begin{tabular}{|c|c|c|c|c|c|}
\hline $\begin{array}{l}\text { Objective } \\
\text { function }\end{array}$ & $\begin{array}{c}\text { Optimization } \\
\text { Algorithm }\end{array}$ & $\begin{array}{c}\text { Modelling } \\
\text { Approach }\end{array}$ & $\begin{array}{l}\text { Decision } \\
\text { variables }\end{array}$ & $\begin{array}{c}\text { Other } \\
\text { characteristics }\end{array}$ & Authors (year) reference \\
\hline $\mathrm{SO}$ & Empirical & $3 \mathrm{D}-\mathrm{N}$ & GP & IEP & Legat and Marchal (1993) [127] \\
\hline $\mathrm{SO}$ & Empirical & $3 \mathrm{D}-\mathrm{N}$ & GP & IEP & Tran-Cong and Phan-Thien (1988) [129] \\
\hline $\mathrm{SO}$ & Empirical & $\mathrm{A}$ & GP & & Hurez et al. (1996) [130] \\
\hline $\mathrm{SO}$ & Empirical & $3 \mathrm{D}-\mathrm{N}$ & GP & & Švábík et al. (1999) [131] \\
\hline $\mathrm{SO}$ & Empirical & $3 \mathrm{D}-\mathrm{N}$ & GP & IEP & Gifford (2003) [132] \\
\hline $\mathrm{SO}$ & Empirical & $3 \mathrm{D}-\mathrm{N}$ & $\mathrm{GP}(3)$ & & Rezaei Shahreza et al. (2010) [133] \\
\hline SO & Simplex & $3 \mathrm{D}-\mathrm{N}$ & GP & & Coupez et al. (1999) [134] \\
\hline $\mathrm{SO}$ & Regression & $3 \mathrm{D}-\mathrm{N}$ & $\mathrm{MP}$ & & Ready and Schaub (1999) [135] \\
\hline $\mathrm{SO}$ & Regression & $3 \mathrm{D}-\mathrm{N}$ & GP(22) & & Elgeti et al. (2012) [136] \\
\hline $\mathrm{SO}$ & Regression & $3 \mathrm{D}-\mathrm{N}$ & $\mathrm{GP}(171)$ & IEP & Pauli et al. (2013) [137] \\
\hline $\mathrm{SO}$ & Gradient & $3 \mathrm{D}-\mathrm{N}$ & MP & & Sienz et al $(1998,2010)[138,139]$ \\
\hline $\mathrm{SO}$ & Gradient & $3 \mathrm{D}-\mathrm{N}$ & GP & & Szarvasy et al. (2000) [140] \\
\hline $\mathrm{SO}$ & ES & $3 \mathrm{D}-\mathrm{N}$ & $\mathrm{MP}$ & & Sienz et al. (1999) [141] \\
\hline $\mathrm{SO}$ & Gradient & $2 \mathrm{D}-\mathrm{N}$ & $\mathrm{KP}$ & & Ettinger et al. $(2004,2004)[142,143]$ \\
\hline $\mathrm{SO}$ & Gradient & $2 \mathrm{D}-\mathrm{N}$ & $\mathrm{KP}(2-46]$ & & Ettinger et al. (2012) [144] \\
\hline $\mathrm{SO}$ & SA & $3 \mathrm{D}-\mathrm{N}$ & GP(3) & & Yilmaz et al. (2014) [145] \\
\hline $\mathrm{SO}$ & Feedback Control & $3 \mathrm{D}-\mathrm{N}$ & GP & IEP & Spanjaards et al. (2021) [146] \\
\hline WS(2) & Simplex & $3 \mathrm{D}-\mathrm{N}$ & GP & & Nóbrega et al. $(2002,2003)[147,148,149]$ \\
\hline WS(2) & Simplex & $3 \mathrm{D}-\mathrm{N}$ & GP & & Carneiro et al. (2004) [150] \\
\hline WS(4) & Gradient & $3 \mathrm{D}-\mathrm{N}$ & $\mathrm{GP}(8)$ & & Zhang et al. (2019) [154] \\
\hline
\end{tabular}

Sienz et al. [138, 139] applied a gradient optimization method based on a sensitivity analysis to design a flow balanced profile die. The same method was used to maximize the velocity at the die exit of another die, using as design variable the land height for the inner branches, the solutions being evaluated by a 3D numerical commercial code, and the optimized results being assessed experimentally [140]. An expert-system driven optimization was also employed [141]. Ettinger et al. [142] and Ettinger [143] proposed a methodology to design profile extrusion dies for Poly(vinyl chloride) (PVC) involving modelling, parameterization techniques, optimization strategies, and the determination of material parameters. Parametrization was based on key-points (KP) with two coordinates $(\mathrm{x}, \mathrm{y})$ and a radius (i.e., the design variables), while flow modelling was carried out with FE performed on 2D die cross-section slices. The optimization problem was solved employing a gradient optimization algorithm, but other strategies were also tested (global and sequential optimization schemes, height approximation method and parallel decoupled scheme), with a view to flow balancing. Later, the authors designed several complex window profiles with the aim of guaranteeing that the right quantity of material is delivered to all parts of the die exit. They fixed between 2 and 46 design variables and used the gradient optimization method based on the calculation of the sensitivities obtained from the rates of change of the objective function with respect of the decision variables [144].

Yilmaz et al. [145] determined the height of the thick channel and the length of the narrow channel of a L-shape profile die that would balance the flow, using simulated annealing together with a kriging meta-model to estimate the modelling results based on 3D numerical computations. Very recently, Spanjaards et al. [146] proposed to solve the IEP using the theory of feedback control, which in practice corresponds to evaluate new solu- 
tions (obtained from a parameter found through trial-and-error) by the modelling program. The methodology was applied to a rectangular channel geometry, with the aim of defining the curved sides of the adapter by minimizing the effects of extrudate-swell.

Finally, some authors considered the use of multiple objectives during the optimization. Nóbrega et al. [147, 148, 149] and Carneiro et al. [150] proposed an optimization methodology based on the simplex method to design a rectilinear profile die. As can be seen in Figure 9(A), the flow channel comprises a parallel zone, a pre-parallel zone, a transition zone and an adapter, but only the first two were considered in the design. Two decision variables were used, the length and thickness of the parallel zone, and the objective function corresponds to the weighted sum of the flow balance and of the length/thickness ratio of the zones to be optimized. Figure 9(B) displays the evolution of the objective function during the twelve optimization iterations. Convergence is attained after the third iteration, the improvements obtained after the ninth iteration being due to mesh refinement. The authors compared the performance of the non-linear Simplex method with a trialand-error procedure, but no conclusion about the best method was clearly reported [151]. The optimization results were assessed experimentally [152, 153]. Zhang et al. [154] applied a gradient method based on a sensitivity analysis of a response surface obtained from 3D numerical modelling relating the objective function with the design variables, to optimize an L-shape profile die. The design variables were the parameters of spline curves based on 8 control points, the objective function was the weighted sum of maximization of flow balance and extrudate-swell homogeneity, and minimization of points displacement and dimensional tolerance.
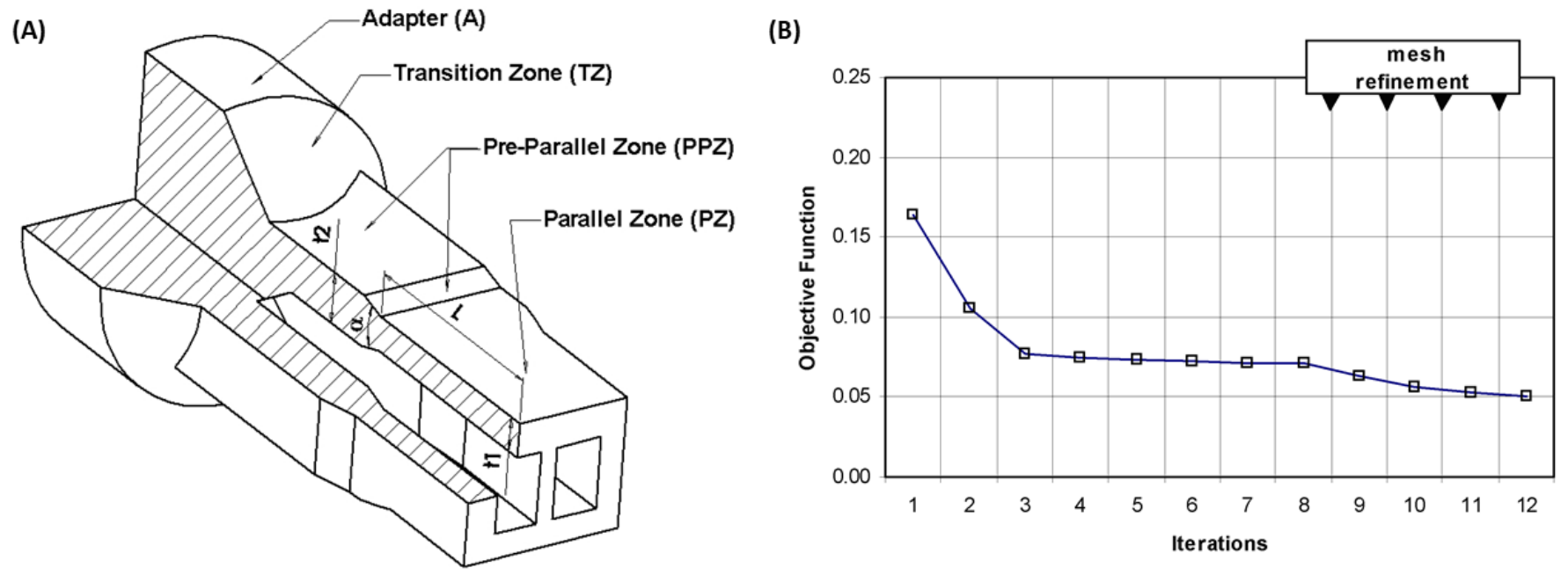

Figure 9. Optimization of a die for the production of a hollow profile: (A) flow channel layout, and decision variables (length and thickness of the parallel zone) and (B) evolution of the weighted sum (objective function) along 12 iterations (adapted from [149]).

\subsubsection{Calibrators}

The design of calibrators is linked to that of profile dies, as they must assure that the cross-section of the extrudate stands within the defined tolerances. For that purpose, the calibrator should cool the extrudate contour uniformly, until an outer layer of polymer has solidified and so its geometry is preserved. Thus, the design of calibrators involves the definition of the number and length of the units to be used, and for each, the number, location and diameter(s) of the cooling channels. Table 6 identifies the previous optimization studies on this topic.

Fradette et al. [155] seems to have pioneered the scientific design of calibrators for profile extrusion. The strategy included a modelling routine (3D numerical modelling), an objective function (the weighted sum of minimizing the cooling time and maximizing the cooling uniformity), decision variables (48 variables defining locations and diameter of 16 cooling channels) and optimization algorithm (gradient optimization). 
Nóbrega and Carneiro [156] used the simplex method to optimize a calibration system comprising three units separated by two annealing zones, the results being obtained by a 3D numerical modelling code. The system was defined by eight geometry related decision variables (length of calibrators and of the annealing zones, temperature of the cooling fluid in each calibrator). Subsequently [157], the number of calibrators was taken as additional decision variable, and a MOEA with two objectives (minimization of the final extrudate average temperature and of the corresponding standard deviation). Duan and Zhang [158] optimized the location and diameter of the cooling channels, considering the weighted sum of two objectives (maximizing the cooling uniformity and the efficiency), but little detail is given on the optimization procedure. Finally, Ren et al. [159] applied EA to optimize a calibrator based on 3D numerical simulations, assuming the weighted sum of two objectives (maximization cooling uniformity and efficiency), with the aim to define the location and diameter of a variable number of cooling channels.

Table 6. Previous publications on the optimization of calibrators for extruded profiles.

\begin{tabular}{|c|c|c|c|c|c|}
\hline $\begin{array}{c}\text { Objective } \\
\text { function }\end{array}$ & $\begin{array}{c}\text { Optimization } \\
\text { Algorithm } \\
\end{array}$ & $\begin{array}{c}\text { Modelling } \\
\text { Approach }\end{array}$ & $\begin{array}{l}\text { Decision } \\
\text { variables }\end{array}$ & $\begin{array}{c}\text { Other } \\
\text { characteristics }\end{array}$ & Authors (year) reference \\
\hline $\mathrm{SO}$ & Simplex & $3 \mathrm{D}-\mathrm{N}$ & $\mathrm{GP}(5)$ & & Nóbrega and Carneiro (2005) [156] \\
\hline $\mathrm{AS}(2)$ & Empirical & $3 \mathrm{D}-\mathrm{N}$ & GP(n) & & Duan and Zhang (2014) [158] \\
\hline $\mathrm{AS}(2)$ & Gradient & $3 \mathrm{D}-\mathrm{N}$ & $\mathrm{GP}(48)$ & & Fradette et al. (1996) [155] \\
\hline $\mathrm{AS}(2)$ & EA & $3 \mathrm{D}-\mathrm{N}$ & GP(n) & & Ren et al. (2010) [159] \\
\hline $\mathrm{MO}$ & EA & $3 \mathrm{D}-\mathrm{N}$ & GP(8) & & Nóbrega et al. (2008) [157] \\
\hline
\end{tabular}

\section{Conclusions}

This review discussed the application of optimization methods to solve real problems in extrusion, namely for single and twin screw extruders, extrusion dies and calibrators. It was shown that equating processing challenges as optimization problems is much more efficient than relying on empirical knowledge, or in the use of simulation tools on a trial and error basis.

Regardless of the specific processing routine being analyzed, it is evident that there is a strong interdependence between the objective function (i.e., the system performance), the optimization algorithm and data collecting (i.e., experimental or computational data). Selecting a specific optimization algorithm depends on the features of the problem and whether the goal is to optimize one or several objectives. Aspects such as the scarcity of data, the possibility of generating data during the optimization, as well as the time required to obtain such data must be take into consideration as well.

The second part of this review will focus on the application of optimization approaches to molding processes (injection and blow molding, thermoforming). Trends in process optimization will be also discussed.

Funding: This research was funded by NAWA-Narodowa Agencja Wymiany Akademickiej, under grant PPN/ULM/2020/1/00125 and European Union's Horizon 2020 research and innovation programme under the Marie Skłodowska-Curie Grant Agreement No 734205-H2020-MSCA-RISE-2016. The authors also acknowledge the funding by FEDER funds through the COMPETE 2020 Programme and National Funds through FCT (Portuguese Foundation for Science and Technology) under the projects UID-B/05256/2020, UID-P/05256/2020.

Acknowledgments: In this section, you can acknowledge any support given which is not covered by the author contribution or funding sections. This may include administrative and technical support, or donations in kind (e.g., materials used for experiments).

Conflicts of Interest: The authors declare no conflict of interest."

\section{References}

1. Plastics the facts 2020, Plastics Europe: Association of Plastics Manufactures, https://www.plasticseurope.org/en/resources/publications/4312-plastics-facts-2020 accessed on 18th May 2021. 
2. Tadmor, Z.; Gogos, C.G. Principles of Polymer Processing, 2nd ed.; Wiley: New York, US, 2006.

3. Maddock, B.H. A Visual Analysis of Flow and Mixing in Extruder Screws. SPE J. 1959, 15, 383-389.

4. Agassant, J.F.; Avenas, P.; J-Ph. Sergent, J.Ph.; Carreau, P.J. Polymer Processing: Principles and Modeling, Carl Hanser Verlag: Munich, Germany, 1991.

5. Osswald, A.T.; Hernández-Ortiz, P.J. Polymer Processing: Modeling and Simulation, Carl Hanser Verlag: Munich, Germany, 2006.

6. Baird, G.D.; Collias, I.D. Polymer Processing: Principles and Design, 2nd ed., Wiley: Hoboken, US, 2014.

7. Gooneie, A.; et al. A Review of Multiscale Computational Methods in Polymeric Materials. Polymers 2017, 9, 16, doi:10.3390/polym9010016.

8. Chan, I.Ch. A Scientific Approach to Screw Design. J. Reinf. Plast. Compos. 1998, 17, 1096-1109, doi.org/10.1177/073168449801701204.

9. Carneiro, O.; Nóbrega, J.M.; Pinho, F.T.; Oliveira, P.J. Computer Aided rheological Design of Extrusion Dies for Profiles. J. Mater. Process. Technol. 2001, 114, 75-86.

10. Jin, Y.; Wang, H.; Chugh, T.; Guo, D.; Miettinen, K. Data-Driven Evolutionary Optimization: An Overview and Case Studies. IEEE Trans. Evol. Comput. 2019, 23, 442-458, doi: 10.1109/TEVC.2018.2869001.

11. Ibañez, R.; Casteran, F.; Argerich, C.; Ghnatios, C.; Hascoet, N.; Ammar, A.; Cassagnau, P.; Chinesta, F. On the Data-Driven Modeling of Reactive Extrusion. Fluids 2020, 5, 94, doi:org/10.3390/fluids5020094.

12. Kasat, R.B.; Ray, A.K.; Gupta, S.K. Applications of Genetic Algorithm in Polymer Science and Engineering. Mater. Manuf. Process. 2003, 18, 523-532, doi:org/10.1081/AMP-120022026.

13. Oduguwa, V.; Tiwari, A.; Roy, R. Evolutionary computing in manufacturing industry: an overview of recent applications. Appl. Soft Comput. 2005, 5, 281-299, doi:org/10.1016/j.asoc.2004.08.003.

14. Nastaj, A.; Wilczyński, K. Optimization and Scale-Up for Polymer Extrusion. Polymers 2021, 13, 1547, doi:org/10.3390/polym13101547.

15. Denysiuk, R.; Gonçalves, N.; Pinto, R.; Silva, H.; Duarte, F.; Nunes, J.; Gaspar-Cunha, A. Optimization of Injection Stretch Blow Molding: Part I - Defining Part Thickness Profile. Int. Polym. Process. 2019, 34, 314-323, doi:org/10.3139/217.3746.

16. Pinto, R.S.; Silva, H.M.; Duarte, F.M.; Nunes, J.P.; Gaspar-Cunha, A. Neuroevolutionary Multiobjective Optimization of Injection Stretch Blow Molding Process in the Blowing Phase. Comput. Methods Appl. Sci. 2021, 55, 307-318, doi:org/10.1007/978-3-030-57422-2_20.

17. Deb, K. Optimization for Engineering Design: Algorithms and Examples, Prentice-Hall: New Delhi, India, 1995.

18. Deb, K. Multi-Objective Optimization using Evolutionary Algorithms, Wiley: New York, US, 2001.

19. Carlos Coello, C.; Lamont, B.G.; van Veldhuizen, A.D. Evolutionary Algorithms for Solving Multi-Objective Problems, 2nd ed.; Springer, New York, US, 2007.

20. Miettinen, K. Nonlinear multiobjective optimization, Springer: Boston, Massachusetts, US, 2012.

21. Afsar, B.; Miettinen, K.; Ruiz, F. Assessing the Performance of Interactive Multiobjective Optimization Methods: A Survey. ACM Comput. Surv. 2021, 54, Article 85, doi:org/10.1145/3448301.

22. Deb, K.; Pratap, A.; Agarwal, S.; Meyarivan, T.A.M.T. A fast and elitist multiobjective genetic algorithm: NSGA-II. IEEE Trans. Evol. Comput. 2002, 6, 182-197, doi:10.1109/4235.996017.

23. Zitzler, E.; Laumanns, M.; Thiele, L. SPEA2: Improving the strength Pareto evolutionary algorithm. Technical Report 103, Computer Engineering and Networks Laboratory (TIK), Swiss Federal Institute of Technology (ETH), Zurich, Switzerland, May 2001.

24. Li, H.; Zhang, Q. Multiobjective optimization problems with complicated Pareto sets, MOEA/D and NSGA-II. IEEE Trans. Evol. Comput. 2009, 13, 284-302.

25. Zitzler, E.; Künzli, S. Indicator-Based Selection in Multiobjective Search. In: Yao X. et al. (eds) Parallel Problem Solving from Nature - PPSN VIII. PPSN 2004. Lecture Notes in Computer Science 2004, 3242. Springer, Berlin, Heidelberg, 832-842.

26. Beume, N., Naujoks, B., Emmerich, M. SMS-EMOA: Multiobjective selection based on dominated hypervolume. Eur. J. Oper. Res. 2007, 181, 1653-1669.

27. Emmerich, M.; Beume, N.; Naujoks, B. An EMO Algorithm Using the Hypervolume Measure as Selection Criterion. Proceedings of Evolutionary Multi-Criterion Optimization (EMO 2005), Guanajuato, Mexico, 9-11 March 2005.

28. McMullen, P.R. An ant colony optimization approach to addressing a JIT sequencing problem with multiple objectives. Artif. Intell. Eng. 2001, 15, 309-317.

29. Mason, K.; Duggan, J.; Howley, E. Multi-objective dynamic economic emission dispatch using particle swarm optimisation variants. Neurocomputing 2017, 270, 188-197, doi:10.1016/j.neucom.2017.03.086.

30. Suman, B.; Kumar, P. A survey of simulated annealing as a tool for single and multiobjective optimization. J. Oper. Res. Soc. 2006, 57, 1143-1160, doi:10.1057/palgrave.jors.2602068.

31. Mezura-Montes E.; Reyes-Sierra M.; Coello C.A.C. Multi-objective Optimization Using Differential Evolution: A Survey of the State-of-the-Art. In Advances in Differential Evolution. Studies in Computational Intelligence; Springer, Berlin, Heidelberg, Germany, 2008, 143, 173-196, https://doi.org/10.1007/978-3-540-68830-3_7.

32. Gaspar-Cunha, A.; Covas, J.A. Robustness in Multi-Objective Optimization Using Evolutionary Algorithms. Comput. Optim. Appl. 2008, 39, 75-96.

33. Gaspar-Cunha, A.; Ferreira, J.; Recio, G. Evolutionary Robustness Analysis for Multi-Objective Optimisation: Benchmark Problems. Struct. Multidiscipl. Optim. 2014, 49, 771-93. 
34. Ferreira, J.; Fonseca, C.; Gaspar-Cunha, A. Methodology to Select Solutions for Multi-Objective Optimization Problems: Weighted Stress Function Method. J. Multi-Crit. Decis. Anal. 2017, 24, 103-120.

35. Underwood, W.M. Experimental method for designing extrusion screws. Chem. Eng. Prog. 1962, 58, 59-65.

36. Tadmor, Z.; Klein, I. Engineering Principles of Plasticating Extrusion, Van Nostrand Reinhold Co.: New York, US, 1970.

37. Maddock, B.H.; Smith, D.J. Extruder Design by Computer Printout. SPE J. 1972, 28, 12-17.

38. Helmy, H.A.A.; Parnaby, J. Computer-Aided Optimal Melt Screw Design. Polym. Eng. Sci. 1976, 16, 437-449.

39. Potente, H.; Hanhart, W.; Klarholz, B.; Schöppner, V. Optimizing extruder screws by simulation. Kunstst. Plast. 1992, 82, 939-944.

40. Wortberg, J.; Klarholz, B.; Meyer-Katona, S. Expert-knowledge-based analysis of extrusion process. Kunstst. 1994, 84, 2630 .

41. Chung, I.Ch. Screw Design, High Performance Screws, and Scale-Up, in Extrusion of Polymers: Theory \& Practice, 3rd ed, Carl Hanser Verlag GmbH \& Co.: Munich, Germany, 2019, 309-364.

42. Rauwendaal, Ch. Polymer extrusion, Hanser Publishers: Munich, Germany, 1986.

43. Altinkaynak, A. Three dimensional finite element simulation of polymer melting and flow in a single-screw extruder: optimization of screw channel geometry. PhD Thesis, Michigan Technological University, Houghton, 2010. https://doi.org/10.37099/mtu.dc.etds/346.

44. Potente, H.; Klarholz, B. Systematic Optimisation of Single-Screw Plasticating Units. Proceedings of PPS 9 Annual Meeting, Manchester, England, 5-8 April 1993, 353-354.

45. Potente, H.; Klarholz, B. A Computer Aided Engineering Concept for the Design and Optimisation of a Single-Screw Plasticating Units. Proceedings of PPS 10 Annual Meeting, Akron, Ohio, US, 5-8 April 1994, 35-36.

46. Potente, H.; Zelleröhr, M. Quality-Functions for the Optimisation of Single-Screw Plasticating Units. Proceedings of PPS 12 Annual Meeting, Sorrento, Italy, 27-31 May 1996, 345-346.

47. Potente, H.; Zelleröhr, M. Optimisation of Single-Screw Extruders with Statistical Methods. Proceedings of PPS13 Annual Meeting, Secausus, New Jork, US, 10-13 June 1997.

48. Potente, H.; Krell, B. Screw optimization by means of DOE and multiple regression. Proceedings of the 55th Annual Technical Conferences of the Society of Plastics Engineers (ANTEC 1997), Toronto, Ontario, Canada, 27 April - 2 May 1997, 135139.

49. Wilczyński, K.; Nastaj, A.; Krutysz, P. Optymalizacja Procesu Wytłaczania Jednoślimakowego Tworzyw Sztucznych. Metoda Statystyczna. Mechanik 2003, 10, 618.

50. Wilczyñski, K. SSEM: a computer model for a polymer single-screw extrusion. J. Mater. Process. Technol. 2001, 109, 308313, doi:org/10.1016/S0924-0136(00)00821-9.

51. Wilczyński, K.; Nastaj, A.; Abramczyk, P. Optymalizacja Procesu Wytłaczania Jednoślimakowego Tworzyw Sztucznych. Metoda Sieci Neuronowych. Mechanik 2004, 7, 470.

52. Thibodeau, C.A.; Lafleur, P.G. Computer Design and Screw Optimization. Proceedings of the 58th Annual Technical Conference of the Society of Plastics Engineers (ANTEC 2000), Orlando, Florida, US, 7-11 May 2000, $276-282$.

53. Thibodeau, C.A.; Lafleur, P.G. Computer Design and Screw Optimization. Proceedings of the Polymer Processing Society 16th Annual Meeting (PPS-16), Shanghai, China, 18-23 June 2000, 15.

54. Nastaj, A.; Wilczyński, K. Process Optimization for Single Screw Extrusion of Polymeric Materials-Simulation Studies. Polimery 2018, 63, 297-304.

55. Nastaj, A.; Wilczyński, K. Optimization for Starve Fed/Flood Fed Single Screw Extrusion of Polymeric Materials. Polymers 2020, 12, 149-165.

56. Abeykoon, Ch.; Li, K.; McAfee, M; Martin, P.J.; Niu, Q.; Kelly, A.L.; Deng, J. A new model based approach for the prediction and optimisation of thermal homogeneity in single screw extrusion. Control Eng. Pract. 2011, 19, 862-874, doi:org/10.1016/j.conengprac.2011.04.015.

57. Gaspar-Cunha, A., Covas, J. A., Oliveira, P. Optimization of Polymer Extrusion With Genetic Algorithms. IMA J. Math. Appl. Bus. Indust. 1998, 9, 267-277, doi:org/10.1093/imaman/9.3.267.

58. Covas, J.A.; Cunha, A.G.; Oliveira, P. An Optimization Approach to Practical Problems in Plasticating Single Screw Extrusion. Polym. Eng. Sci. 1999, 39, 443-456.

59. Gaspar-Cunha, A.; Covas, J.A. The Design of Extrusion Screw: An Optimization Approach. Int. Polym. Proc. 2001, 16, 229240.

60. Covas, J.A.; Gaspar-Cunha, A. Optimisation-Based Design of Extruders. Plast. Rubber Compos.: Macromol. Eng. 2004, 33, 416-425.

61. Domingues, N.; Gaspar-Cunha, A.; Covas, J.A. A Quantitative Approach to Assess the Mixing Ability of Single Screw Extruders for Polymer Extrusion. J. Polym. Eng. 2012, 32, 81-94.

62. Gaspar-Cunha, A.; Gonçalves, L.; Covas, J.A. Application of Evolutionary Algorithms to the Design of Barrier Screws for Single Screw Extruders. In Applied Soft Computing Technologies: The Challenge of Complexity, ed. by Abraham, A.; Baets, B.; Koppen, M.; Nickolay, B. Berlin Heidelberg: Springer Verlag; Berlin, Germany, 2006, 763-774.

63. Covas, J.A.; Gaspar-Cunha, A. Extrusion Scale-up: An Optimization-based Methodology. Int. Polym. Proc. 2009, $24,67-82$.

64. Gaspar-Cunha, A.; Covas, J.A. A Universal Engineering Scale-Up Approach Using Multi-Objective Optimization. Int. J. Nat. Lang. Computing 2014, 4, 17-30.

65. Denysiuk, R.; Recio, G.; Covas, J.A.; Gaspar-Cunha, A. Using Multiobjective Optimization Algorithms and Decision Making Support to Solve Polymer Extrusion Problems. Polym. Eng. Sci. 2018, 58, 493-502, doi.org/10.1002/pen.24732. 
66. Deb, K.; Bandaru, S.; Greiner, D.; Gaspar-Cunha, A.; Tutum, C.C. An Integrated Approach to Automated Innovization for Discovering Useful Design Principles: Case Studies from Engineering. App. Soft Comput. 2014, 15, 42-56. doi: 10.1016/j.asoc.2013.10.011.

67. Potente, H.; Ansahl, J.; Klarholz, B. Design of Tightly Intermeshing Co-Rotating Twin Screw Extruders. Int. Polym. Proc. 1994, 9, 11-25.

68. Potente, H.; Bastian, M.; Flecke, J. Design of a compounding extruder by means of the SIGMA simulation software. Adv. Polym. Techn. 1999, 18, 147-170.

69. Vainio, T.P.; Harlin, A.; Seppälä, J.V. Screw optimization of a co-rotating twin-screw extruder for a binary immiscible blend. Polym. Eng. Sci. 1995, 35, 225-232, doi:org/10.1002/pen.760350302.

70. Berzin, F.; Tara, A.; Vergnes, B. Optimization and scale-up of starch cationization in a twin screw extruder. Polym. Eng. Sci. 2007, 47, 814-823, doi:org/10.1002/pen.20759.

71. Maridass, B.; Gupta, B.R. Performance optimization of a counter rotating twin screw extruder for recycling natural rubber vulcanizates using response surface methodology. Polym. Test. 2004, 23, 377-385, doi:org/10.1016/j.polymertesting.2003.10.005.

72. Ulitzsch, S.; Bäuerle, T.; Chassé, T.; Lorenz, G.; Kandelbauer, A. Optimizing the Process Efficiency of Reactive Extrusion in the Synthesis of Vinyltrimethoxysilane-Grafted Ethylene-Octene-Copolymer (EOC-g-VTMS) by Response Surface Methodology. Polymers 2020, 12, 2798, doi:org/10.3390/polym12122798.

73. Fukuda, G.; Bigio, D.I.; Andersen, P.; Wetzel, M. A new scale-up approach for dispersive mixing in twin-screw compounding. AIP Conference Proceedings 2015, 1664, 100007.

74. Potente, H.; Thümen, A. Method for the Optimisation of Screw Elements for Tightly Intermeshing, Co-rotating Twin Screw Extruders. Int. Polym. Proc. 2006, 21, 149-154.

75. Zhang, G.; Zhang, M.; Jia, Y. Multi-objective optimization of reactive extrusion by genetic algorithms. J. Appl. Polym. Sci., 2015, 132, 41862, doi:org/10.1002/app.41862.

76. Gaspar-Cunha, A.; Poulesquen, A.; Vergnes, B.; Covas, J.A. Optimization of Processing Conditions for Polymer Twin-Screw Extrusion. Int. Polym. Proc. 2002, 17, 201-213.

77. Vergnes, B.; Della Valle, G.; Delamare, L. A global computer software for polymer flows in corotating twin screw extruders. Polym. Eng. Sci., 1998, 38, 1781.

78. Gaspar-Cunha, A.; Covas, J.A.; Vergnes, B. Defining the Configuration of Co-Rotating Twin-Screw Extruders with Multiobjective Evolutionary Algorithms. Polym. Eng. Sci. 2005, 45, 1159-1173.

79. Teixeira, C.; Covas, J.A.; Stützle, T.; Gaspar-Cunha, A. Engineering an Efficient Two-Phase Local Search Algorithm for the Co-Rotating Twin-Screw Extruder Configuration Problem. Int. Trans. Oper. Res. 2011, 18, 271-291.

80. Teixeira, C.; Gaspar-Cunha, A.; Covas, J.A. Flow and Heat Transfer along the Length of a Co-Rotating Twin Screw Extruder. Polym. Plast. Technol. Eng. 2012, 51, 1567-1577.

81. Teixeira, C.; Covas, J.A.; Stützle, T.; Gaspar-Cunha, A. Multi-Objective Ant Colony Optimization for the Twin-Screw Configuration Problem. Eng. Optimiz. 2012, 44, 351-371.

82. Teixeira, C.; Covas, J.A.; Stützle, T.; Gaspar-Cunha, A. Hybrid Algorithms for the Twin--Screw Extrusion Configuration Problem. App. Soft Comput. 2014, 23, 298-307.

83. Teixeira, C.; Covas, J.A.; Berzin, F.; Vergnes, B.; Gaspar-Cunha, A. Application of Evolutionary Algorithms to the Definition of the Optimal Twin-Screw Extruder Configuration for Starch Cationization. Polym. Eng. Sci. 2011, 51, 330-340.

84. Gaspar-Cunha, A.; Covas, J.A. A Scaling-up Methodology for Co-Rotating Twin-Extruders. Proceedings of the 27th Annual Meeting of the Polymer Processing Society (PPS-27), Marrakesh, Morocco, 10-14 May 2011, 1-6.

85. Rakos, R.; Sebastian, D. Design and optimization of extrusion dies using computer based simulations. Adv. Polym. Techn. 1990, 10, 297-307, doi:10.1002/adv.1990.060100406.

86. Matsubara, Y. Geometry design of a coat-hanger die with uniform flow rate and residence time across the die width. Polym. Eng. Sci. 1997, 19, 169-172, doi:10.1002/pen.760190302.

87. Matsubara, Y. Design of coat-hanger sheeting dies based on ratio of residence times in manifold and slot. Polym. Eng. Sci. 1980, 20, 716-719, doi:10.1002/pen.760201103.

88. Matsubara, Y. Residence time distribution of polymer melt in the T-die. Polym. Eng. Sci. 1980, 20, 212-214, doi:10.1002/pen.760200308.

89. Matsubara, Y. Flat die geometry - A note. Polym. Eng. Sci. 1988, 28, 1275, doi:10.1002/pen.760281910.

90. Winter, H.H.; Fritz, H.G. Design of dies for the extrusion of sheets and annular parisons: The distribution problem. Polym. Eng. Sci. 1986, 26, 543-553, doi:10.1002/pen.760260805.

91. Liu, T.J.; Hong, C.N.; Chen, K.C. Computer-aided analysis of a linearly tapered coat-hanger die. Polym. Eng. Sci. 1988, 28, 1517-1526, doi:10.1002/pen.760282302.

92. Lee, K.Y.; Liu, T.J. Design and analysis of a dual-cavity coat-hanger die. Polym. Eng. Sci. 1989, 29, 1066-1075, doi:10.1002/pen.760291513.

93. Liu, T.J.; Liu, L.D.; Tsou, J.D. A unified lubrication approach for the design of a coat-hanger die. Polym. Eng. Sci. 1994, 34, 541-550, doi:10.1002/pen.760340702.

94. Yu, Y.W.; Liu, T.J. A simple numerical approach for the optimal design of an extrusion die. J. Polym. Res. 1998, 5, 1-7, doi:10.1007/s10965-006-0033-z.

95. Na, S.Y.; Kim, D.H. Three-dimensional modelling of non-newtonian fluid flow in a coat-hanger die. Korean J. Chem. Eng. $1995,12,236-243$. 
96. Huang, Y.; Gentle, C.R.; Hull, J.B. A comprehensive 3-D analysis of polymer melt flow in slit extrusion dies. Adv. Polym. Technol. 2004, 23, 111-124, doi:10.1002/adv.20002.

97. Chen, C.; Jen, P.; Lai, F.S. Optimization of the coathanger manifold via computer simulation and an orthogonal array method. Polym. Eng. Sci. 1997, 37, 188-196, doi:10.1002/pen.11661.

98. Razeghiyadaki, A.; Zhang, D.; Wei, D.; Perveen, A. Optimization of Polymer Extrusion Die Based on Response Surface Method. Processes 2020, 8, 1043, doi:org/10.3390/pr8091043.

99. Razeghiyadaki, A.; Wei, D.; Perveen, A.; Zhang, D. A Multi-Rheology Design Method of Sheeting Polymer Extrusion Dies Based on Flow Network and the Winter-Fritz Design Equation. Polymers 2021, 13, 1924, doi:10.3390/polym13121924.

100. Lebaal, N.; Schmidt, F.M.; Puissant, S. Optimization of 3D die extrusion using response surface method, Proceedings of 9th International Conference on Material Forming ESAFORM, Glasgow, United Kingdom, April 2006, 703-706.

101. Lebaal, N.; Schmidt, F.; Puissant, S. Design and optimization of three-dimensional extrusion dies, using constraint optimization algorithm. Finite Elem. Anal. Des. 2009, 45, 333-340, doi:10.1016/j.finel.2008.10.008.

102. Lebaal, N.; Schmidt, F.; Puissant, S. Optimisation of extrusion flat die design and die wall temperature distribution, using Kriging and response surface method. Int. J. Mater. Prod. Technol. 2010, 38, 307, doi:10.1504/ijmpt.2010.032107.

103. Lebaal, N.; Puissant, S.; Schmidt, F.M.; Schläfli, D. An optimization method with experimental validation for the design of extrusion wire coating dies for a range of different materials and operating conditions. Polym. Eng. Sci. 2012, 52, 2675-2687, doi:10.1002/pen.23203.

104. Smith, D.E.; Tortorelli, D.A.; Tucker, C.L. Optimal design for polymer extrusion. Part I: Sensitivity analysis for nonlinear steady-state systems. Comput. Methods Appl. Mech. Eng. 1998, 167, 283-302. doi:10.1016/s0045-7825(98)00129-7.

105. Smith, D.E.; Tortorelli, D.A.; Tucker, C.L. Optimal design for polymer extrusion. Part II: Sensitivity analysis for weaklycoupled nonlinear steady-state systems. Comput. Methods Appl. Mech. Eng. 1998, 167, 303-323, doi:10.1016/s00457825(98)00130-3.

106. Smith, D.E. Design sensitivity analysis and optimization for polymer sheet extrusion and mold filling processes. Int. J. Numer. Methods Eng. 2003, 57, 1381-1411, doi:10.1002/nme.782.

107. Smith, D. E. An optimisation-based approach to compute sheeting die designs for multiple operating conditions, SPE ANTEC Tech. 2003, 315-319.

108. Sun, Y.; Gupta, M. Optimization of a flat die geometry. Proceedings of SPE Annual Technical Conference, Chicago, Illinois, US, 16-20 May 2004, 3307-3311.

109. Bates, S.J.; Pittman, J.F.T.; Sienz, J.; Langley, D.S. Enhancing slit die performance by optimization of restrictor profiles. Polym. Eng. Sci. 2003, 43, 1500-1511, doi:10.1002/pen.10127.

110. Sienz, J.; Bates, S.J.; Pittman, J.F.T. Flow restrictor design for extrusion slit dies for a range of materials: Simulation and comparison of optimization techniques. Finite Elem. Anal. Des. 2006, 42, 430-453, doi:10.1016/j.finel.2005.06.008.

111. Michaeli, W.; Kaul, S. Approach of an Automatic Extrusion Die Optimization. J. Polym. Eng. 2004, 24, doi:10.1515/polyeng.2004.24.1-3.123.

112. Meng, K.; Zhao, Z.L. Optimal Design of the Curvilinear Tapered Coat-Hanger Die. Appl. Mech. Mater. 2011, 121-126, 10141018, doi:10.4028/www.scientific.net/amm.121-126.1014.

113. Sun, Y.; Wang, X. Optimization of air flow field of the melt blowing slot die via numerical simulation and genetic algorithm. J. Appl. Polym. Sci. 2010, 115, 1540-1545, doi:10.1002/app.31109.

114. Meng, K.; Wang, X.; Huang, X. Optimal design of the coat-hanger die used for producing melt-blown fabrics by finite element method and evolution strategies. Polym. Eng. Sci. 2009, 49, 354-358, doi:10.1002/pen.21281.

115. Meng, K.; Wang, XH; Chen QG Analysis and Design of a Broad-Width Coat-Hanger Die in the Melt Blowing Process. Fibres Text. East. Eur. 2012, 20, 44-47.

116. Han, W.; Wang, X. Optimal geometry design of the coat-hanger die with uniform outlet velocity and minimal residence time. J. Appl. Polym. Sci. 2012, 123, 2511-2516, doi:10.1002/app.34827.

117. Smith, D.; Wang, Q. Optimal Polymer Sheeting Die Design for Multiple Operation Conditions. Proceedings of 45th AIAA/ASME/ASCE/AHS/ASC Structures, Structural Dynamics \& Materials Conference, Palm Springs, California, US, 1922 April 2004.

118. Smith, D.E.; Wang, Q. Optimization-based design of polymer sheeting dies using generalized Newtonian fluid models. Polym. Eng. Sci. 2005, 45, 953-965, doi:10.1002/pen.20347.

119. Wang, Q.; Smith, D.E. Analysis of the fluid-structure interaction in the optimization-based design of polymer sheeting dies. J. Appl. Polym. Sci. 2006, 103, 3994-4004, doi:10.1002/app.25517.

120. Wang, Q.; Smith, D. Incorporating Fluid-Structure Interaction in the Optimization-Based Design of Polymer Sheeting Dies. Proceedings of 11th AIAA/ISSMO Multidisciplinary Analysis and Optimization Conference, Portsmouth, Virginia, US, 68 September 2006.

121. Zhang, H.; Chen-Yu, W.; Chai, Y.; Guan, T.Y. Structure optimisation of coat-hanger die based on the multi-objective and design of experiment analysis. Int. J. Theor. Appl. Multiscale Mech. 2020, 3, 206-228, doi:org/10.1504/IJTAMM.2020.112756.

122. Lee, P.C.; Dietsche, L.; Dooley, J.; Parashar, S. Improving Film Die Flow Uniformity Using Optimization Methods Coupled with Finite Element Computational Fluid Dynamics (CFD) Analysis. Int. Polym. Proc. 2015, 30, 51-62, doi:10.3139/217.2887.

123. Han, W.; Wang, X. Multi-objective optimization of the coat-hanger die for melt-blowing process. Fibers Polym. 2012, 13, 626-631, doi:10.1007/s12221-012-0626-6. 
124. Han, W.; Wang, X. Optimal geometry design of double coat-hanger die for melt blowing process. Fibers Polym. 2014, 15, 1190-1196, doi:10.1007/s12221-014-1190-z.

125. Huang, C.C. A systematic approach for the design of a spiral mandrel die. Polym. Eng. Sci. 1998, 38, 573-582, doi:10.1002/pen.10220.

126. Mu, Y.; Zhao, G.; Wu, X.; Zhang, C. An optimization strategy for die design in the low-density polyethylene annular extrusion process based on FES/BPNN/NSGA-II. Int. J. Adv. Manuf. Technol. 2010, 50, 517-532, doi:10.1007/s00170-010-2556-z.

127. Legat, V.; Marchal, J.M. Die design: An implicit formulation for the inverse problem. Int. J. Numer. Methods Fluids 1993, 16, 29-42, doi:10.1002/fld.1650160103.

128. Pittman, J. Computer-aided design and optimization of profile extrusion dies for thermoplastics and rubber: a review. Proceedings of the Institution of Mechanical Engineers, Part E: J. Proc. Mech. Eng. 2011, 225, 280-321.

129. Tran-Cong, T.; Phan-Thien, N. Die design by a boundary element method. J. NonNewton. Fluid Mech. 1998, 30, 37-46, doi:10.1016/0377-0257(88)80016-8.

130. Hurez, P.; Tanguy, P.A.; Blouin, D. A new design procedure for profile extrusion dies. Polym. Eng. Sci. 1996, 36, 626-635, doi:10.1002/pen.10450.

131. Švábík, J.; Plaček, L.; Sáha, P. Profile Die Design Based on Flow Balancing: Balancing with Flow Separation" Int. Polym. Proc. 1999, 14, 247-253, https://doi.org/10.3139/217.1550.

132. Gifford, W.A. Compensating for die swell in the design of profile dies. Polym. Eng. Sci. 2003, 43, 1657-1665, doi:10.1002/pen.10139.

133. Rezaei, S.A.; Behravesh, A.H.; Bakhshi, J.M.; Soury, E. Design, optimization, and manufacturing of a multiple-thickness profile extrusion die with a cross flow. Polym. Eng. Sci. 2010, 50, 2417-2424, doi:10.1002/pen.21770.

134. Coupez, Y.; Isaac, A.; Nouatin, H. Optimisation in forming using the simplex method and preliminary results on an explicit 3D viscoelastic solution. Proceedings of 2nd ESAFORM, Guimaraes, Portugal, 13-16 April 1999, 477-480.

135. Reddy, M.P.; Schaub, E.G. Design and optimisation of three dimensional extrusion dies using adaptive finite element method. Proceedings of ANTEC 1999, Kaneohe, Hawaii, September 1999, 63-67.

136. Elgeti, S.; Probst, M.; Windeck, C.; Behr, M.; Michaeli, W.; Hopmann, C. Numerical shape optimization as an approach to extrusion die design. Finite Elem. Anal. Des. 2012, 61, 35-43, doi:10.1016/j.finel.2012.06.008.

137. Pauli, L.; Behr, M.; Elgeti, S. Towards shape optimization of profile extrusion dies with respect to homogeneous die swell. J. NonNewton. Fluid Mech. 2013, 200, 79-87, doi:10.1016/j.jnnfm.2012.12.002.

138. Sienz, J.; Da Silva, C.E.K.; Hinton, E.; Szarvasy, I. Optimisation of PVC window profile dies. In Computational Mechanics New Trends and Applications, S. Idelsohn, E. Oñate and E. Dvorkin (Eds.) (CCIMNE, Barcelona, Spain 1998.

139. Sienz, J.; Goublomme, A.; Luege, M. Sensitivity analysis for the design of profile extrusion dies. Comput. Struct. 2010, 88, 610-624, doi:10.1016/j.compstruc.2010.02.003.

140. Szarvasy, I.; Sienz, J.; Pittman, J.F.T.; Hinton, E. Computer aided optimisation of profile extrusion dies: definition and assessment of the objective function. Int. Polym. Proc., 2000, 15, 28-39.

141. Sienz, J.; Da Silva, C.E.K.; Hinton, E.; Pittman, J.F.T.; Marchal, J.M. Expert-system driven optimisation of extrusion dies. Proceedings of 1st ASMO UK/ISSMO Conference on Engineering design optimization, Ilkley, West Yorkshire, UK, 8-9 July 1999, 337-344.

142. Ettinger, H.J.; Sienz, J.; Pittman, J.F.T.; Polynkin, A. Parameterization and optimization strategies for the automated design of uPVC extrusion dies. Struct. Multidiscip. Optim., 2004, 28, 180-194.

143. Ettinger, H.J. Development of optimization and parameterization techniques applied to extrusion die design optimization of PVC profile dies. PhD Thesis, Swansea University, Swansea, 2004.

144. Ettinger, H.; Pittman, J.F.T.; Sienz, J. Optimization-driven design of dies for profile extrusion: Parameterization, strategy, and performance. Polym. Eng. Sci. 2012, 53, 189-203, doi:10.1002/pen.23228.

145. Yilmaz, O.; Gunes, H.; Kirkkopru, K. Optimization of a profile extrusion die for flow balance. Fibers Polym. 2014, 15, 753761, doi:10.1007/s12221-014-0753-3.

146. Spanjaards, M.M.A.; Hulsen, M.A.; Anderson, P.D. Die shape optimization for extrudate swell using feedback control. J. NonNewton. Fluid Mech. 2021, 293, 104552, doi:10.1016/j.jnnfm.2021.104552.

147. Nobrega, J.M.; Carneiro, O.S.; Oliveira, O.S.; Pinho, F.T. Flow balance optimisation of profile dies. Proceedings of PPS18, Guimaraes, Portugal, 16-20 June 2002.

148. Nobrega, J.M.; Carneiro, O.S.; Pinho, F.T.; Oliveira, P.J. Optimisation of the flow distribution in profile extrusion dies. Proceedings of ANTEC 2002, San Francisco, California, 5-9 May 2002, 122-126.

149. Nobrega, J.M.; Carneiro, O.S.; Oliveira, P.J.; Pinho, F.T. Flow balancing in extrusion dies for thermoplastic profiles. Part I. Automatic design. Int. Polym. Proc. 2003, 18, 298-306.

150. Carneiro, O.S.; Nobrega, J.M. Recent developments in automatic die design for profile extrusion. Plast. Rubber Compos. 2004, 33, 400-408.

151. Carneiro, O.S.; Nobrega, J.M.; Oliveira, P.J.; Pinho, F.T. Flow balancing in extrusion dies for thermoplastics profiles, Part II. Influence of the design strategy. Int. Polym. Proc., 2003, 18, 307-312.

152. Nobrega, J.M.; Carneiro, O.S.; Pinho, F.T. Flow balancing in extrusion dies for thermoplastic profiles. Part III: Experimental assessment. Int. Polym. Process., 2004, 19, 225-235.

153. Carneiro, O.S.; Nobrega; J.M.; Pinho, F.T.; Oliveira, P. J. Automatic balancing of profile extrusion dies: experimental assessment. Proceedings of ANTEC 2004, Navy Pier, Chicago, Illinois, 16-20 May 2004, 91-95. 
154. Zhang, G.; Huang, X.; Li, S.; Deng, T. Optimized Design Method for Profile Extrusion Die Based on NURBS Modeling. Fibers Polym. 2019, 20, 1733-1741, doi:10.1007/s12221-019-1168-y.

155. Fradette, L.; Tanguy, P.A.; Thibault, F.; Sheehy, P.; Blouin, D.; Hurez, P. Optimal Design in Profile Extrusion Calibration. J. Polym. Eng. 1995, 14, 295-322, doi:10.1515/polyeng.1995.14.4.295.

156. Nóbrega, J. M.; Carneiro, O. S. Recent Developments in Profile Extrusion: Automatic Design of Extrusion Dies and Calibrators. Anais do $9^{\circ}$ Congresso Brasileiro de Polímeros, Campina Grande, Brazil, December. 2007.

157. Nóbrega, J.M.; Carneiro, O.S.; Gaspar-Cunha, A.; Goncalves, N. Design of Calibrators for Profile Extrusion - Optimizing Multi-Step Systems. Int. Polym. Proc. 2008, 23, 331-338.

158. Duan, L.; Zhang, Y. Optimization Design in Cooling Channels of Calibrator for Plastic Profile Extrusion Based on Numerical Simulation. Appl. Mech. Mater. 2014, 494-495, 677-680, doi:10.4028/www.scientific.net/amm.494-495.677.

159. Ren, L.; Yang, R.; Zhang, W. Topology and Shape Optimization Design in Cooling System of Vacuum Calibrator for Plastic Profile Extrusion. Proceedings of 2010 International Conference on E-Product E-Service and E-Entertainment, Henan, China, 7-9 Nov. 2010. 